\title{
SUPPLIER SELECTION FOR HOUSING DEVELOPMENT BY AN INTEGRATED METHOD WITH INTERVAL ROUGH BOUNDARIES
}

\author{
Zhiying ZHANG (1) ${ }^{1}$, Huchang LIAO (1) 1,2,*, Abdullah AL-BARAKATI (1) ${ }^{2}$, \\ Edmundas Kazimieras ZAVADSKAS (D) ${ }^{3}$, Jurgita ANTUCHEVIČIENE (iD) 4 \\ ${ }^{1}$ Business School, Sichuan University, 610064, Chengdu, China \\ ${ }^{2}$ Faculty of Computing and Information Technology, King Abdulaziz University, 21589, Jeddah, Saudi Arabia \\ ${ }^{3}$ Institute of Sustainable Construction, Vilnius Gediminas Technical University, 10223, Vilnius, Lithuania \\ ${ }^{4}$ Department of Construction Management and Real Estate, Vilnius Gediminas Technical University,
} 10223, Vilnius, Lithuania

Received 06 September 2019; accepted 06 February 2020

\begin{abstract}
Residential whole-decoration is an important initiative for housing industrialization in China. Selecting the most suitable component supplier for housing development is of great significance for both property developers and buyers in the implementation of such a strategy. To address such a problem, this study uses hesitant fuzzy linguistic term sets to express the inaccurate judgments of individuals and then introduces a novel probability aggregation approach based on interval rough boundaries to enable a realistic presentation of the collective evaluations of a group. Then, we propose a hybrid multi-expert multiple criteria decision-making model by integrating the Best Worst Method (BWM) and Combined Compromise Solution (CoCoSo) method based on the interval rough boundaries. A case study about the supplier selection for housing development is carried out, which demonstrates the feasibility and applicability of our proposed hybrid model. A comparison study is also performed to further validate the robustness of the model.
\end{abstract}

Keywords: multi-criteria decision making, supplier selection for housing development, interval rough boundaries, Combined Compromise Solution method, Best-Worst method, hesitant fuzzy linguistic term set, probabilistic linguistic term set.

\section{Introduction}

As environmental protection in China is more and more prominent, energy saving and environment friendly housing development becomes one of the top priorities for the Chinese government (Zhang et al., 2011; Shi et al., 2012). For the conventional sale mode of Chinese housing, most residential houses sold on the market are unfurnished, which means that owners need to fit-out their residences in the way of separate decoration. In this situation, the supply of construction equipment and components fails to form a supply chain system of scale production and serialization, which results in low quality of decoration, poor equipment versatility, and unreasonable performance cost ratio of residential houses. Meanwhile, it also brings problems such as the waste of fit-out materials and the difficulty in handling construction waste (Ministry of Housing and Urban-Rural Development of the People's Republic of China [MOHURD], 2008).
A residential house with whole-decoration is also called a finished residence, which refers that all fixed surfaces of a functional space are completely paved or finished, and the basic equipment, such as the kitchen and bathroom, are all installed before the property developer turns the residence to the owner. In 1999, the concept of whole-decoration was first proposed in China (Ministry of Housing and Urban-Rural Development of the People's Republic of China [MOHURD], 1999). Until now, many provinces in China, such as Shanghai ${ }^{1}$, Hainan ${ }^{2}$, and

\footnotetext{
1 The promotion of residential whole-decoration strategy in Shanghai, available at http://www.gov.cn/jrzg/2012-10/02/ content_2237316.htm

2 The promotion of residential whole-decoration strategy in Hainan, available at http://www.gov.cn/xinwen/2017-05/23/ content_5196084.htm
}

*Corresponding author. E-mail: liaohuchang@163.com 
Zhejiang ${ }^{3}$, have begun to promote whole-decoration residential houses. The main reasons are as follows:

1) The advanced management system of real estate enterprises can be used to effectively manage the fit-out process, thus significantly reducing labor, material waste, and realizing resource conservation;

2) Property developers can integrate their supplier resources, shorten the circulation of fit-out materials, and reduce the fit-out cost through large-scale purchase, so as to develop high-quality residential products with a relatively low cost;

3) The close integration of construction and fit-out process is conducive to standardizing the residential fit-out behavior and reducing damage to the structure of a building, which is helpful for extending the operation life of a building, and further improving the living environment level.

The residential whole-decoration is an initiative to develop housing industrialization, and is also a mainstream development trend of the Chinese real estate market (Ministry of Housing and Urban-Rural Development of the People's Republic of China [MOHURD], 2013). Although appropriate strategies and actions have been taken by different levels of government in China to make fit-out activities sustainable, there are still many problems in the current implementation process, such as the high price of furnished housing, the insufficient supply of fit-out materials caused by short-term and large-scale purchasing demands, and the negative effect on living comfort caused by the quality problems of fit-out components (for example, the marble cracking of kitchen operation table and the expansion of cabinet door panel).

Components procurement for housing development is an important process of the implementation of residential whole-decoration. Supplier selection, as the first step of component procurement, is vital for the quality and cost control of residential houses. The selection process is supported by multi-criteria decision making (MCDM) methods, which consist of three major stages: evaluation, prioritization and selection of alternatives (Lam et al., 2010; Luo et al., 2016; Safa et al., 2014; Seth et al., 2018). To the best of our knowledge, few literature considered the MCDM methods on component supplier selection for housing development, which motivates the research question of this paper as how to use an appropriate MCDM model to select the optimal component supplier for housing development.

In MCDM approaches for suppliers' performance evaluation, multiple factors should be taken into consideration to obtain a comprehensive and robust result. One of the new utility-based MCDM methods is the CoCoSo (Combined Compromise Solution) method (Yazdani et al., 2019a, b), which is characterized by three aggre-

\footnotetext{
3 The promotion of residential whole-decoration strategy in Zhejiang, available at http://www.gov.cn/xinwen/2017-02/02/ content_5164705.htm
}

gation strategies to obtain the moderate performances of alternatives. Due to the simple calculation process and the robustness of decision results, the CoCoSo method has been successfully applied in several fields like supply chain finance (Wen et al., 2019) and engineering management (Yazdani et al., 2019a). In addition, when applying MCDM methods, several weight determining methods have been proposed for criteria. Best worst method (BWM), initially introduced by Rezaei (2015), is one of the most effective criteria weighting approaches with less pairwise comparisons and a higher consistency ratio (Mi et al., 2019).

In the evaluation process, usually, a group of experts are invited to give their evaluation information. The experts are not always knowledgeable enough to give precise evaluations, especially in a complicated environment. In this sense, fuzzy methods are flexible to express inaccurate and fuzzy judgments. The hesitant fuzzy linguistic term set (HFLTS) (Rodriguez et al., 2011), which received considerable attention in recent years (Liao et al., 2018), is a powerful qualitative information representation tool since it can provides several linguistic terms in conjunction with a context-free grammar. In addition, traditional aggregation methods of HFLTSs failed to reflect the preferences of a group. It is observed that an interesting aggregation approach named the probability aggregation method was proposed by $\mathrm{Wu}$ and Liao (2018) to integrate individuals' opinions. However, such an aggregation method failed to take into account the vagueness of the judgments given by a group. The rough number (Zhai et al., 2008) contains the information that indicates not only the preference of an individual expert but also the diversity of all other experts' opinions. The better the agreements of individual expert's perceptions, the smaller the interval rough boundaries will be. In this sense, to solve the shortcoming of the hesitant fuzzy linguistic aggregation, we propose a novel probability aggregation approach to integrate individuals' evaluation values based on the interval rough boundaries.

Based on the above analysis, this study dedicates to proposing a hybrid MCDM model combining the BWM and CoCoSo method based on interval rough boundaries. The novelty of this study can be summarized as follows:

1) We propose a novel probabilistic aggregation approach based on interval rough boundaries, which enables a realistic presentation of collective evaluations by considering the vagueness of the evaluation information given by multi-experts.

2) The BWM with interval rough boundaries is developed to determine the weights of criteria for cognitive complex multi-expert decision-making problems.

3) The CoCoSo method with interval rough boundaries is proposed, and the calculation procedure of the CoCoSo method under the probabilistic linguistic environment is given.

4) A hybrid multi-expert multiple criteria decisionmaking model by integrating the BWM and CoCoSo method based on interval rough boundaries 
is developed to help property developers select the "best" construction component suppliers in the cognitive complex decision-making environment, which is conducive to the promotion of residential whole-decoration, and further promoting resource conservation utilization in the construction sector.

The rest of this paper is organized as follows: Section 1 briefly reviews the supplier evaluation problems in the construction industry. Section 2 introduces related concepts and the probabilistic aggregation approach with interval rough boundaries. Section 3 presents a hybrid multi-expert multiple criteria decision-making model to solve cognitive complex decision-making problems. Section 4 provides a case study on a supplier decision-making problem for housing development. The study ends with conclusions in the last section.

\section{Literature review}

In this section, firstly, we review some literature about the supplier evaluation model in the construction industry. Then, we give a short overview of the MCDM methods involved in this paper.

\subsection{Brief review on supplier evaluation in construction industry}

To ensure the quality and reduce cost in an increasingly compete construction industry, SCM (Supply Chain Management) has proved to be an indispensable tool. The first step to implement the SCM is supplier selection. An effective and efficient supplier selection model can help construction enterprises select the "best" supplier at the right cost in the right quality (Lam et al., 2010). The existing studies of supplier evaluation in construction industry mainly focused on two types: material or equipment supplier selection, and service supplier selection.

For the supplier selection of construction materials, Lam et al. (2010) constructed a selection model based on the fuzzy PCA (Principal Component Analysis). Safa et al. (2014) developed an integrated model for the efficient procurement of construction materials, primarily through the use of the TOPSIS method. Under the background of housing industrialization in China, Luo et al. (2016) put forward an evaluation index system for supplier selection regarding green housing components by considering 47 indicators. In their evaluation, to reduce the influence of subjective factors, they applied a model combining the Kent index method with the catastrophe theory. Wang et al. (2017) proposed a framework by integrating the building information modeling and geographic information system to select a resilient construction component supplier. Seth et al. (2018) demonstrated the impact of competitive conditions on the supplier evaluation for construction supply chains. For the selection of service suppliers, Eshtehardian et al. (2013) investigated 23 most effective criteria for supplier selection by a questionnaire survey, and integrated the ANP (Analytic Network Process) with AHP (Analytic Hierarchy Process) to select appropriate suppliers for construction and civil engineering companies. Yin et al. (2017) established 17 criteria, and integrated the interval-valued intuitionistic fuzzy geometric weighted Heronian mean operator with a multi-target nonlinear programming model to obtain a comprehensive evaluation result by considering the influence of constructors' subjective preferences and objective information on criteria. Matić et al. (2019) presented a combined model for sustainable constructor selection through a full consistency method and a rough COPRAS (Complex Proportional Assessment) method. Yazdani et al. (2019b) extended the CoCoSo method with grey numbers to measure the performances of suppliers, and to achieve the importance of supplier criteria, a combination of two weighting methods, namely, the DEMATEL (Decision Making Trial and Evaluation Laboratory) and BWM, were used in their study.

From the above review of supplier selection in the construction industry, we can find that the MCDM theory is effective for supplier selection in the construction industry. In addition, supplier selection is valued by construction enterprises since it is of great importance in improving their competitiveness. However, the literature that focused on comprehensive MCDM methods for supplier selection in construction industry under the cognitive complex decision-making environment, especially for the construction component suppliers, is limited. Thus, it is urgent to develop a comprehensive and effective MCDM model to select an appropriate construction component supplier for construction enterprises.

\subsection{A short overview of MCDM methods}

MCDM methods can be divided into two categories: outranking-based methods and utility-based methods. For massive alternatives, the outranking-based methods, such as the ELECTRE (Elimination Et Choice Translating Reality) and PROMETHEE (Preference Ranking Organization Method for Enrichment Evaluation), are limited due to complicated calculations. The utility-based methods, such as the TOPSIS (Technique for Order Preference by Similarity to Ideal Solution), VIKOR (Vlsekriterijumska Optimizacija I Kompromisno Resenje) and MULTIMOORA (Multiplicative MultiObjective Optimization by Ratio Analysis), are effective due to their applicability and simplicity (Corrente et al., 2013; Liao \& Wu, 2020). The CoCoSo method (Yazdani et al., 2019b), as a utility-based method, considers the compensation effects among criteria by a unique structure that presents the weighted average normalized decision matrix and weighted geometric matrix together. It can give a comprehensive ranking result by using three aggregation strategies, and the calculation process is relatively easy compared with other MCDM methods. This method has been extended to solve practical problems within different cases. For instance, Wen 
et al. (2019) extended the CoCoSo method to hesitant fuzzy linguistic context and applied the hesitant fuzzy linguistic CoCoSo method to select third-party logistics service providers for financial institutions; Yazdani et al. (2019a) proposed a hybrid model by extending the CoCoSo method with grey numbers to measure the performance of suppliers in a construction company.

BWM (Rezaei, 2015) is a weighting approach based on linear programming. Compared with the AHP method, it requires less pairwise comparisons, and the obtained weights are more reliable since comparisons in the BWM are carried out with a higher consistency ratio. Due to its advantages, the BWM has received widespread attention in various fields. For example, Pamučar et al. (2018) modified the traditional BWM within the rough set context, and presented the algorithm of the hybrid BWM-MABAC (Multi-Attributive Border Approximation area Comparison) model based on interval-valued fuzzy-rough numbers to evaluate firefighting helicopters; Liao et al. (2019b) extended the BWM to the hesitant fuzzy linguistic environment for hospital performance evaluation; Liao et al. (2019c) integrated the BWM and ARAS method for digital supply chain finance supplier selection; Yazdani et al. (2019a) proposed a structured BWM-CoCoSo model for sustainable supplier selection.

Due to the complexity of numerous indicators and ambiguity in human thinking, there are difficulties in representing evaluation information in accurate values (Pamučar et al., 2018). Since Rodriguez et al. (2011) first proposed the HFLTS, it has been extended to various MCDM methods to solve practical problems, such as the HFL-AHP (Tüysüz \& Şimşek, 2017), HFL-BWM (Liao et al., 2019b), HFL-VIKOR (Liao et al., 2014), and HFL-QFD (Quality Function Deployment) (Onar et al., 2016). However, the HFLTS can express only individual evaluations. While some aggregation methods of HFLTSs can be used to integrate hesitant fuzzy linguistic (HFL) evaluations, the information loss is serious (Wu \& Liao, 2018). Pang et al. (2016) extended the HFLTS to the probabilistic linguistic term set (PLTS) by assigning probability to each linguistic term. The PLTS has gained many scholars' attention (Liao et al., 2019a; Zhang et al., 2017; Gou et al., 2017; Wu \& Liao, 2019; Liao et al., 2020; Mi et al., 2020). Wu and Liao (2018) introduced an aggregation method called the probability aggregation method to integrate the opinions of individuals. However, it failed to consider the vagueness of information given by a group of experts.

Rough numbers were derived from the concept of approximation in the rough theory proposed by Zhai et al. (2008). The boundaries of rough numbers can avoid the subjectivity and measure the vagueness by providing an overall view about the diversity of all experts' opinions. The more diverse of a group's judgments are, the larger the interval rough boundaries of the preferences classes involved will be. Although little research has exploited the interval rough boundaries, the applicability of rough num- bers has been fully justified in practical decision-making process. Song et al. (2013) proposed the rough group AHP and rough group TOPSIS to optimize the design concept evaluation under the subjective environment. Zhu et al. (2015) developed a novel rough number-based VIKOR to evaluate the design concept alternatives. Pamučar et al. (2017) combined the rough interval DEMATEL with the ANP to enable more objective expert evaluation of criteria in a subjective environment than a crisp approach. Pamučar et al. (2018) modified the traditional BWM and MABAC method by integrating the rough approach, which eliminated the subjectivity that exists when defining the borders of fuzzy sets. For the application of supplier selection in a construction company, Stević et al. (2017) extended the COPRAS and MULTIMOORA method by rough numbers.

Considering the limitation of the probability aggregation method proposed by $\mathrm{Wu}$ and Liao (2018) and the usefulness of the interval rough boundaries in representing vague information, this paper proposes a novel probabilistic aggregation approach based on interval rough boundaries. Then, based on the BWM and CoCoSo method, we construct an efficient hybrid MCDM model to select the "best" construction component supplier for construction enterprises under the cognitive complex decision-making environment.

\section{A probability aggregation approach based on interval rough boundaries}

In this section, we first introduce the concepts of HFLTS and PLTS. After that, we develop a novel probabilistic aggregation approach based on interval rough boundaries to enable a realistic presentation of the collective evaluations.

\subsection{Concepts of HFLTS and PLTS}

Evaluating qualitative variables by linguistic terms is intuitive and flexible for experts since linguistic terms are in line with human way of thinking and reasoning ( $\mathrm{Za}-$ deh, 1975). To evaluate a linguistic variable, a linguistic term set (LTS) should be defined first. A general LTS is $S_{(1)}=\left\{s_{\alpha} \mid \alpha=0,1, \cdots, 2 \tau\right\}$, where $\tau$ is a positive integer and the subscripts are evenly distributed around the medium one (Herrera et al., 1995). Considering the different thinking mode of experts, the unbalanced semantics for an ordered set of linguistic terms were initially discussed by Torra (1996), and to facilitate understanding and calculation, $\mathrm{Xu}$ (2005) defined a subscript-symmetric LTS as $S_{(2)}=\left\{s_{t} \mid t=-\tau, \cdots,-1,0,1, \cdots, \tau\right\}$. Specific LTSs should be chosen according to practical decision-making problems so that the theoretical analyses of these models are not affected by the differences of LTSs.

The HFLTS, which allows people to give more than one linguistic term as the value of a linguistic variable by assigning them with equal importance, has been proved to be an effective tool to express individuals' judgments. It was proposed by Rodriguez et al. 
(2011) and redefined in mathematical form by Liao et al. (2015). Let $S$ be an LTS. An HFLTS on $X, H_{S}$, is in mathematical form of $\left.H_{S}=\left\{<x_{i}, h_{s}\left(x_{i}\right)\right\rangle \mid x_{i} \in X\right\}$, where $h_{s}\left(x_{i}\right)=\left\{s_{\varphi_{l}}\left(x_{i}\right) s_{\varphi_{l}}\left(x_{i}\right) \in S, l=1,2, \cdots, L_{i}\right\}$ with $L_{i}$ being the number of linguistic terms in $h_{s}\left(x_{i}\right)$ and $s_{\varphi_{l}}\left(x_{i}\right)$ $\left(l=1,2, \cdots, L_{i}\right)$ being the continuous terms in $S . h_{s}\left(x_{i}\right)$ denotes the possible degrees of the linguistic variable $x_{i}$ to $S$ and is termed as a hesitant fuzzy linguistic element (HFLE).

As the HFLTS was widely used, people found that the linguistic terms are associated with different probabilities in some situations. For example, people might think that the environmental level of an integral kitchen cabinet supplier is "somewhat good" in 70\% and "good" in 30\%. Here, the numbers " $70 \%$ " and " $30 \%$ " can be seen as the probabilities of different linguistic terms. To cope with probabilities, Pang et al. (2016) extended the HFLTS and proposed the probabilistic linguistic term set (PLTS) as $h_{s}(p)=\left\{s^{(k)}\left(p^{(k)}\right) \mid s^{(k)} \in S, p^{(k)} \in[0,1], \sum p^{(k)} \in[0,1], k=1,2, \cdots, K\right\}$, where $K$ is the number of different linguistic terms in $h_{s}(p)$, and $s^{(k)}\left(p^{(k)}\right)$ is the $k$-th linguistic term $s^{(k)}$ associated with the probability $p^{(k)}$.

\subsection{Rough numbers and interval rough boundaries}

Rough set is an effective tool to represent knowledge. In the rough set theory, an information system with decision attributes is called a decision table, denoted by $S=\left\langle U, Q=\left(A^{\prime} \cap D\right), V, f\right\rangle$, where $U=\left\{x_{1}, x_{2}, \cdots, x_{i}\right\}$ is a nonempty, finite set of objects, $A^{\prime}=\left\{\alpha_{1}, \alpha_{2}, \cdots, \alpha_{j}\right\}$ is a nonempty, finite set of condition attributes, and $D=\left\{d_{1}, d_{2}, \cdots, d_{s}\right\}$ is a nonempty, finite set of decision attributes. Without loss of generality, a system with a single decision attribute $D=\{d\}$, is considered in this study. In general, it is assumed that $A^{\prime} \cap D=\varnothing$ and each attribute $a \in A^{\prime} \cup D$ forms a mapping $f: U \rightarrow V_{\alpha}$, where $V_{a}$ is the value domain of attribute $\alpha$ (Greco et al., 2001; Li et al., 2016). Each nonempty subset $B \subseteq A^{\prime}$ determines an indiscernibility relation $R_{B}=\left\{\left(x_{n}, x_{m}\right) \in U \times U \mid f\left(x_{n}, a\right)=f\left(x_{m}, a\right), a \in B\right\}$. $R_{B}$ partitions $U$ into a family of disjoint subsets given by $U \mid R_{B}=\left\{[x]_{B} \mid x \in U\right\}$, where $[x]_{B}$ denotes the equivalence class determined by $x$ with respect to subset $B$. The equivalence relation causes the vagueness of two classes. The rough set theory offers a means to describe these vague classes through the lower and upper approximations. For any class $C^{\prime} \subseteq U$ and $B \subseteq A^{\prime}$, the lower approximation of $C$ is presented as $R_{B}\left(C^{\prime}\right)=\cup\left\{[x]_{B} \mid[x]_{B} \subseteq C^{\prime}\right\}$, and the upper approximation is presented as $\overline{R_{B}}\left(C^{\prime}\right)=\cup\left\{[x]_{B} \mid[x]_{B} \cap C^{\prime} \neq \varnothing\right\}$. The lower approximation is called the positive region of $C^{\prime}$ and can be denoted alternatively as $\operatorname{POS}_{B}\left(C^{\prime}\right) . C^{\prime}$ is called a rough set with respect to $B$ if and only if $R_{B}\left(C^{\prime}\right) \neq \overline{R_{B}}\left(C^{\prime}\right)$, and the objects belonging only to the upper approximation but not to the lower approximation compose the boundary region $R B_{B}\left(C^{\prime}\right)=\overline{R_{B}}\left(C^{\prime}\right)-R_{B}\left(C^{\prime}\right)$.

Approximations are important in the rough set theory to deal with uncertainty and vagueness. They only rely on the given data and no subjective information is needed.
To use the approximations to represent the vagueness of human assessments, Zhai et al. (2008) defined rough numbers and their corresponding lower and upper limits, as well as rough boundaries. In the following, we define rough number-related algorithms under the HFL environment for MCDM problems on the basis of the definitions proposed by Zhai et al. (2008):

Let $A=\left\{A_{i} \mid i=1,2, \cdots, m\right\}$ be a set of alternatives, $C=\left\{c_{j} \mid j=1,2, \cdots, n\right\}$ be a set of criteria, and $E=\left\{e_{q} \mid q=1,2, \cdots, Q\right\}$ be a set of experts. An expert's HFL judgment of alternative $A_{i}$ on criterion $c_{j}$ is $h_{S}^{i j(q)}=\left\{s_{\varphi_{1}}^{(q)}, s_{\varphi_{2}}^{(q)}, \cdots, s_{\varphi_{L(q)}}^{(q)}\right\}$. Then, the collective evaluation values of alternative $A_{i}$ on criterion $c_{j}$ can be expressed as $h_{S}^{i j}=\left\{s_{\varphi_{1}}^{(1)}, s_{\varphi_{2}}^{(1)}, \cdots, s_{\varphi_{L(1)}}^{(1)}, \cdots, s_{\varphi_{1}}^{(q)}, s_{\varphi_{2}}^{(q)}, \cdots, s_{\varphi_{L(q)}}^{(q)}, \cdots, s_{\varphi_{1}}^{(Q)}, s_{\varphi_{2}}^{(Q)}, \cdots, s_{\varphi_{L(Q)}}^{(Q)}\right\}$. Suppose that $U^{i j}=\left\{\varphi_{1}^{(1)}, \varphi_{2}^{(1)}, \cdots, \varphi_{L(1)}^{(1)}, \cdots, \varphi_{1}^{(q)}, \varphi_{2}^{(q)}, \cdots\right.$, $\left.\varphi_{L(q)}^{(q)}, \cdots, \varphi_{1}^{(Q)}, \varphi_{2}^{(Q)}, \cdots, \varphi_{L(Q)}^{(Q)}\right\}$ contains all the subscripts of the terms in $h_{S}^{i j}$ and let $y$ be an arbitrary object from $U^{i j}$. There is a set of $Y_{i j}$ classes $G_{i j}=\left\{C_{i j}^{(1)}, C_{i j}^{(2)}, \cdots, C_{i j}^{\left(Y_{\beta}\right)}, \cdots, C_{i j}^{\left(Y_{i j}\right)}\right\}$ in $U^{i j}$. If the classes satisfy $C_{i j}^{(1)}<C_{i j}^{(2)}<\cdots<C_{i j}^{\left(Y_{\beta}\right)}<\cdots<C_{i j}^{\left(Y_{i j}\right)}$, then $\forall y \subset U^{i j}, C_{i j}^{\left(Y_{\beta}\right)} \in G_{i j}, 1 \leq Y_{\beta} \leq Y_{i j}$. The lower approximation and upper approximation of $C_{i j}^{\left(Y_{\beta}\right)}$ can be defined as:

$$
\begin{aligned}
& \overline{A p r}\left(C_{i j}^{\left(Y_{\beta}\right)}\right)=\cup\left\{y \in U \mid G_{i j}(y) \leq C_{i j}^{\left(Y_{\beta}\right)}\right\} ; \\
& \overline{\operatorname{Apr}}\left(C_{i j}^{\left(Y_{\beta}\right)}\right)=\cup\left\{y \in U \mid G_{i j}(y) \geq C_{i j}^{\left(Y_{\beta}\right)}\right\} .
\end{aligned}
$$

The boundary region of $C_{i j}^{\left(Y_{\beta}\right)}$ is given by

$$
\begin{aligned}
& R B\left(C_{i j}^{\left(Y_{\beta}\right)}\right)=\cup\left\{y \in U / G_{i j}(y) \neq C_{i j}^{\left(Y_{\beta}\right)}\right\}= \\
& \left\{y \in U \mid G_{i j}(y)>C_{i j}^{\left(Y_{\beta}\right)}{ }_{i}\right\} \cup\left\{y \in U \mid G_{i j}(y)<C_{i j}^{\left(Y_{\beta}\right)}\right\} .
\end{aligned}
$$

Then, $C_{i j}^{\left(Y_{\beta}\right)}$ can be represented by a rough number $R N\left(C_{i j}^{\left(Y_{\beta}\right)}\right)$, which consists of its corresponding lower limit $\underline{\operatorname{Lim}}\left(C_{i j}^{\left(Y_{\beta}\right)}\right)$ and upper limit $\overline{\operatorname{Lim}}\left(C_{i j}^{\left(Y_{\beta}\right)}\right)$, where

$$
\begin{aligned}
& \underline{\operatorname{Lim}}\left(C_{i j}^{\left(Y_{\beta}\right)}\right)=\frac{1}{M_{l o}} \sum G_{i j}(y) \mid y \in \underline{\operatorname{Apr}}\left(C_{i j}^{\left(Y_{\beta}\right)}\right) ; \\
& \overline{\operatorname{Lim}}\left(C_{i j}^{\left(Y_{\beta}\right)}\right)=\frac{1}{M_{u p}} \sum G_{i j}(y) \mid y \in \overline{\operatorname{Apr}}\left(C_{i j}^{\left(Y_{\beta}\right)}\right) ; \\
& R N\left(C_{i j}^{\left(Y_{\beta}\right)}\right)=\left[\underline{\operatorname{Lim}}\left(C_{i j}^{\left(Y_{\beta}\right)}\right), \overline{\operatorname{Lim}}\left(C_{i j}^{\left(Y_{\beta}\right)}\right)\right],
\end{aligned}
$$

with $M_{l o}$ and $M_{u p}$ being the numbers of objects in $\operatorname{Apr}\left(C_{i j}^{\left(Y_{\beta}\right)}\right)$ and $\overline{A p r}\left(C_{i j}^{\left(Y_{\beta}\right)}\right)$, respectively.

The interval between the lower limit and upper limit is known as the rough boundary, denoted as:

$$
R B\left(C_{i j}^{\left(Y_{\beta}\right)}\right)=\overline{\operatorname{Lim}}\left(C_{i j}^{\left(Y_{\beta}\right)}\right)-\underline{\operatorname{Lim}}\left(C_{i j}^{\left(Y_{\beta}\right)}\right) .
$$

Example 1. Let $S_{(2)}=\left\{s_{-3}=\right.$ very bad, $s_{-2}=$ bad, $s_{-1}=$ somewhat bad, $s_{0}=$ normal, $s_{1}=$ somwhat good, $s_{2}=\operatorname{good}, s_{3}=$ very good be an LTS. Eight experts are invited to evaluate 
Table 1. Comparison of rough numbers and their interval rough boundaries (for Example 1)

\begin{tabular}{|c|c|c|c|c|c|}
\hline Class & Rough number & Lower limit & Upper limit & Rough boundary & $\begin{array}{c}\text { Proportion of evaluation } \\
\text { data }\end{array}$ \\
\hline$C^{(1)}$ & $<0,1.21>$ & 0.00 & 1.21 & 1.21 & $3 / 14$ \\
\hline$C^{(2)}$ & $<0.7,1.55>$ & 0.70 & 1.55 & 0.85 & $1 / 2$ \\
\hline$C^{(3)}$ & $<0.92,2.5>$ & 0.92 & 2.50 & 1.58 & $1 / 7$ \\
\hline$C^{(4)}$ & $<1.21,3>$ & 1.21 & 3.00 & 1.79 & $1 / 7$ \\
\hline
\end{tabular}

the environmental levels of an integral kitchen cabinet suppliers. Suppose that three experts believe it is "somewhat good", expressed as $\left\{s_{1}\right\}$; two consider it is "between normal and somewhat good", expressed as $\left\{s_{0}, s_{1}\right\}$; two think it is "at least somewhat good", denoted as $\left\{s_{1}, s_{2}, s_{3}\right\}$; one holds it is "normal", denoted as $\left\{s_{0}\right\}$. Then, the collective HFLE is $h_{S}=\left\{s_{1}, s_{1}, s_{1}, s_{0}, s_{1}, s_{0}, s_{1}, s_{1}, s_{2}, s_{3}, s_{1}, s_{2}, s_{3}, s_{0}\right\}$,

and $U=\{1,1,1,0,1,0,1,1,2,3,1,2,3,0\}$ which has four classes $G=\left\{C^{(1)}, C^{(2)}, C^{(3)}, C^{(4)}\right\}=\{0,1,2,3\}$. Take class $C^{(3)}$ whose subscript is " 2 " to explain the definition of the rough number. According to Eqs. (1)-(3): $\underline{\operatorname{Apr}}(2)=\cup\{y \in U \mid G(y) \leq 2\}=\{1,1,1,0,1,0,1,1,2,1,2,0\}, \overline{\operatorname{Apr}}(2)=$ $\cup\{y \in U \mid G(y) \geq 2\}=\{2,3,2,3\}, R B(2)=\cup\left\{y \in U \mid G(y) \neq C^{(3)}\right\}=$ $\{1,1,1,0,1,0,1,1,3,1,3,0\}$. By Eqs. (4)-(6), the rough number of $C^{(3)}$ is calculated as: $\underline{\operatorname{Lim}}(2)=\sum G(y)|y \in \underline{\operatorname{Apr}(2)}| M_{l o}=$ 0.92, $\overline{\operatorname{Lim}}(2)=\sum G(y)|y \in \overline{\operatorname{Apr}}(2)| M_{u p}=2.5, \mathrm{RN}(2)=$ $[\underline{\operatorname{Lim}}(2), \overline{\operatorname{Lim}}(2)]=[0.92,2.5]$. The corresponding rough boundary is calculated by Eq. (7) as: $R B(2)=\overline{\operatorname{Lim}}(2)-$ $\operatorname{Lim}(2)=1.58$. Similarly, the rough number related calculations of other classes can be obtained, which are shown in Table 1.

According to the definition, we can see that each class associated with unique subscript value of an evaluation can be denoted by a unique rough number, whose lower and upper limits are computed based on all experts' evaluations for an alternative under a criterion. This is because a rough number contains the information indicating not only the preference of an individual expert but also the diversity of all other experts' opinions. Also, we can find that better agreements of experts' evaluations will lead to smaller rough boundaries of the involved preference classes. For instance, in the given evaluation values, seven experts involve class $C^{(1)}$, while only two experts involve classes $C^{(3)}$ and $C^{(4)}$. In Table 1 , the figure for class $C^{(1)}$ accounts for half of the total number of the given subscripts, while either class $C^{(3)}$ or $C^{(4)}$ accounts for only one-seventh. Thus, class $C^{(1)}$ has smaller rough boundary (0.85) compared with classes $C^{(3)}$ and $C^{(4)}$ (1.58 and 1.79 , respectively), which implies that the class with a larger rough boundary is vaguer or less reliable.

\subsection{A novel probability aggregated approach}

Although the PLTS can express both the flexible qualitative assessment and quantitative probabilistic information, it is difficult in reality to assign the probabilities of the linguistic terms in an expert's evaluation since such assignments are determined based on experience, intuition or subjective perception.

In most cases, experts prefer to use HFLTSs to express their evaluations. Compared with the PLTS in which the probability of each linguistic term depends on experts' subjective judgments, the HFLTS is more objective. However, the HFLTS has some shortcomings in representing collective opinions of a group (Wu \& Liao, 2018). What's more, in the collective decision-making matrix, there indeed exists probability distributions of HFLEs to reflect the different preferences of experts. To avoid these defects, Wu \& Liao (2018) introduced an aggregation method called the probability aggregation method to calculate the weights of linguistic elements corresponding to a group, which is reliable since the group opinions and the preferences of a group can be presented. The algorithm is shown as follows (Wu \& Liao, 2018): let $E=\{e q \mid q=1,2, \cdots, Q\}$ be a set of experts whose weight vector is $\left\{\gamma^{(1)}, \gamma^{(2)}, \cdots, \gamma^{(Q)}\right\}$ and $S$ be an LTS. Suppose that $h_{s}{ }^{(q)}=\left\{s_{\varphi_{l}}{ }^{(q)}(x) \mid s_{\varphi_{l}}{ }^{(q)} \in S, l=1,2, \cdots, L_{q}\right\}(q=1,2, \cdots, Q)$ are $Q$ HFLTs on $S$ given by $Q$ experts. Let $h_{s}=\left\{s_{\varphi_{l}} \mid s_{\varphi_{l}} \in S, l=1,2, \cdots, L\right\}$ be the group HFLE. Then, the weight of $s_{\varphi_{l}}{ }^{(q)}$ in $h_{s}{ }^{(q)}$ is defined as:

$v_{\varphi_{l}}^{(q)}=\left\{\begin{array}{l}1 / L^{(q)}, \text { if } \varphi_{l} \in h_{S}^{(q)} \\ 0, \quad \text { if } \varphi_{l} \notin h_{S}^{(q)}\end{array}, l=1,2, \cdots, L_{q} ; q=1,2, \cdots, Q\right.$

The weight of $h_{s}{ }^{(q)}$ given by expert $e q$ is $\gamma^{(q)}$, for $q=1,2, \cdots, Q$. Then, the weight of $s_{\varphi_{l}}$ in the group HFLE is

$$
p^{\left(\varphi_{l}\right)}=\sum_{q=1}^{Q} v_{\varphi_{l}}^{(q)} \gamma^{(q)}, l=1,2, \cdots, L_{q}
$$

Thus, the group judgment can be expressed as the PLTS

$$
h_{s}(p)=\left\{s_{\varphi_{l}}\left(p^{\left(\varphi_{l}\right)}\right) \mid s_{\varphi_{l}} \in S, p^{\left(\varphi_{l}\right)}=\sum_{q=1}^{Q} v_{\varphi_{l}}^{(q)} \gamma^{(q)}, l=1, \cdots, L_{q}\right\}
$$

With Eq. (10), the judgments given by individual experts in HFLEs can be aggregated into a PLTS. If the experts' judgments are represented by PLTSs, with Eq. (10), the collective PLTS can be obtained when the original probabilities are replaced by $v_{\varphi_{l}}^{(q)}$. If the weights of the experts are not given, the weight vector can be supposed as $\gamma^{(q)}=1 / Q, q=1,2, \cdots, Q$.

Example 2. (Continued to Example 1) Suppose that the weight of each expert is $\gamma^{(q)}=1 / 8$. Take $s_{2}$ as an example. According to Eqs. (8)-(10): we have $p^{(2)}=0.08$, and 


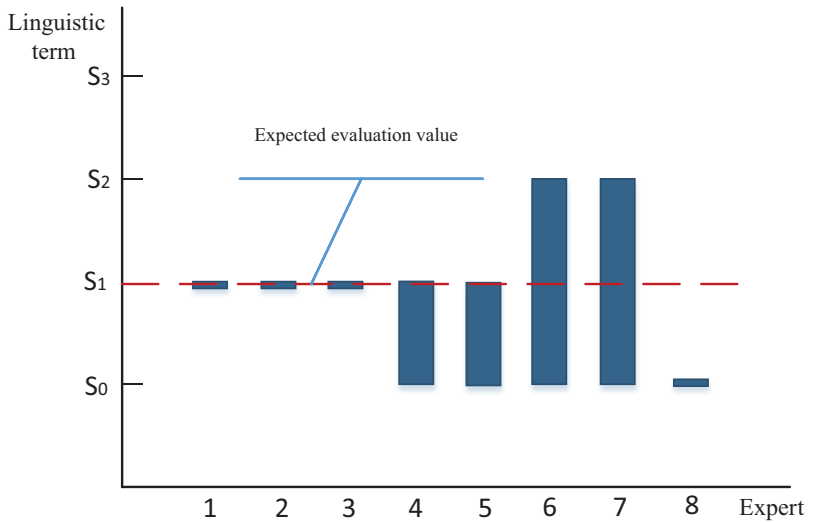

Figure 1. Experts' evaluations in Example 1

then $s_{2}\left(p^{(2)}\right)=s_{2}(0.08)$. The aggregated PLTS of the group is $h_{s}(p)=\left\{\mathrm{s}_{0}(0.25), \mathrm{s}_{1}(0.58), \mathrm{s}_{2}(0.08), \mathrm{s}_{3}(0.08)\right\}$.

However, we may not accept the above result. Based on rational judgment without introducing interval rough boundaries, it can be concluded that the expected evaluation value of the group should be $s_{1}$ (as shown in Figure 1) based on the subscripts' arithmetic mean of the eight experts' evaluations. From Figure 1, we can see that the covering range (number) of $s_{2}$ is the same as that of $s_{3}$, but the distance to the expected evaluation value of $s_{2}$ is closer to $s_{3}$. So, it is unreasonable that $s_{2}$ and $s_{3}$ are assigned with an equal probability in the aggregated PLTS of the group.

As we discussed in Section 2.2, rough numbers depict the preference information of a given expert. In addition, all other experts' opinions are also considered in the calculation process. Generally, the smaller the boundary is, the crisper the number will be. In Example 1, we calculated the interval rough boundaries of the evaluation values' subscripts as: $R B(1)=1.21, R B(1)=0.85, R B(2)=1.58$, $R B(3)=1.79$. According to the definition of interval rough boundaries, class " 2 " is crispier than class " 3 ", so we can conclude that the assigned probability of $s_{2}$ should be greater than $s_{3}$ in the set of the aggregated PLTS. Here, we define a concept named the accuracy degree to adjust the original aggregated probability, which is expressed as:

$$
C D\left(C_{i j}^{\left(Y_{\beta}\right)}\right)=\left\{\begin{array}{c}
\frac{1 / R B\left(C_{i j}^{\left(Y_{\beta}\right)}\right)}{\sum_{Y_{\beta}=1}^{Y_{i j}} 1 / R B\left(C_{i j}^{\left(Y_{\beta}\right)}\right)}, R B\left(C_{i j}^{\left(Y_{\beta}\right)}\right) \neq 0 \\
1, \quad R B\left(C_{i j}^{\left(Y_{\beta}\right)}\right)=0
\end{array}\right.
$$

where: $C D\left(C_{i j}^{\left(Y_{\beta}\right)}\right)$ denotes the accuracy degree of $C_{i j}^{\left(Y_{\beta}\right)}$. $C_{i j}^{\left(Y_{\beta}\right)}$ refers to the $Y^{\beta}$-th subscript class of all experts' HFL evaluation values of alternative $A_{i}$ on criterion $c_{j}$. Then, the PLTS of the collective judgments can be adjusted as:

$$
\begin{aligned}
& h_{s}\left(p^{\star}\right)=\left\{s_{\varphi_{l}}\left(p^{\star\left(\varphi_{l}\right)}\right) \mid s_{\varphi_{l}} \in S, p^{\star\left(\varphi_{l}\right)}=\right. \\
& \left.\left(p^{\left(\varphi_{l}\right)} \times C D\left(C_{i j}^{\left(Y_{\beta}\right)}\right)\right)^{1 / 2} / \sum_{l=1}^{L}\left(p^{\left(\varphi_{l}\right)} \times C D\left(C_{i j}^{\left(Y_{\beta}\right)}\right)\right)^{1 / 2}, l=1,2, \cdots, L\right\},
\end{aligned}
$$

where: $p^{\left(\varphi_{l}\right)}$ is the original probability of $s_{\varphi_{l}}$ in the set of the aggregated PLTS.

Example 3. (Continued to Example 2) According to Eq. (11), we obtain the accuracy degree: $C D(0)=0.26$, $C D(1)=0.37, C D(2)=0.2, C D(3)=0.18$. According to Eq. (12), we can calculate the adjusted probabilities as: $p^{*(0)}=0.26, p^{*(1)}=0.48, p^{*(2)}=0.13, p^{*(3)}=0.12$. Thus, the PLTS of the collective judgment of the group is adjusted to $h_{s}\left(p^{*}\right)=\left\{\mathrm{s}_{0}(0.26), \mathrm{s}_{1}(0.48), \mathrm{s}_{2}(0.13), \mathrm{s}_{3}(0.12)\right\}$.

With Eq. (12), the judgments given by multiple experts in HFLEs can be aggregated into the adjusted PLTS. Since class " 2 " is crispier than class " 3 ", from the results yield by our proposed aggregation method, the assigned probability of $s_{2}$ is greater than $s_{3}$ ( 0.13 and 0.12 , respectively). So, the proposed aggregation method can better integrate individuals' opinions by taking into account the vague degree of the judgments given by a group of experts.

If the rough boundaries of different linguistic terms' subscripts are the same, then, the PLTS of the collective judgments can be directly obtained through the method proposed by Wu and Liao (2018).

Example 4. Let $S_{(2)}=\left\{s_{-3}=\right.$ very bad, $s_{-2}=$ bad, $s_{-1}=$ somewhat bad, $s_{0}=$ normal, $s_{1}=$ somewhat good, $s_{2}=$ good, $s_{3}=$ very good $\}$ be an LTS. Eight experts are invited to evaluate innovation capabilities of integral kitchen cabinet manufacturers. Suppose that two experts believe it is "somewhat good", expressed as $\left\{s_{1}\right\}$; four consider it is "between somewhat good and good", expressed as $\left\{s_{1}, s_{2}\right\}$; two think it is "good", denoted as $\left\{s_{2}\right\}$. The subscripts set of the evaluation values can be obtained as $U=\{1,1,1,2,1,2,1,2,1,2,2,2\}$, which has two classes $G=\left\{C^{(1)}, C^{(2)}\right\}=\{1,2\}$. From Figure 2, we can see that the distances of different linguistic terms to the expected evaluation value are the same. By Eqs. (4)-(7), the interval rough boundaries of the two subscript classes are calculated as $R B(1)=0.5, R B(2)=0.5$. Thus, the adjusted PLTS of the collective judgment is $h_{s}\left(p^{*}\right)=h_{s}(p)=\left\{s_{1}(0.5), s_{2}(0.5)\right\}$, which is the same as that derived by the method of $\mathrm{Wu}$ and Liao (2018).

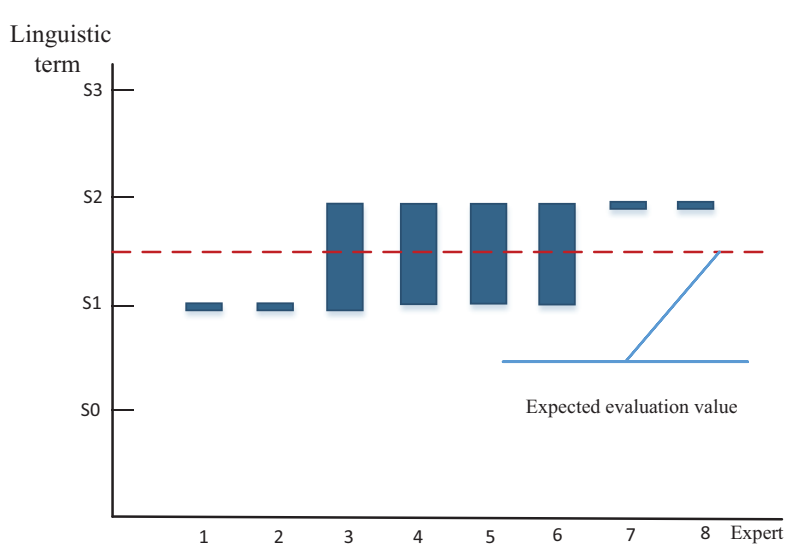

Figure 2. Experts' evaluations in Example 4 


\section{A hybrid multi-expert MCDM method based on the probability aggregation approach with interval rough boundaries}

In this section, the proposed new probabilistic aggregation approach was tested by an MCDM model implemented in two phases: (1) determining the weights of evaluation criteria, and (2) ranking alternatives. To obtain the weights of criteria, the best-worst method (BWM) (Rezaei, 2015) with the probabilistic aggregation approach based on interval rough boundaries was used. After the criteria weights are obtained, a modified combined compromise solution (CoCoSo) method (Yazdani et al., 2019b) based on the probabilistic aggregation approach is applied. The framework of the proposed model is depicted in Figure 3.

\subsection{A modified BWM with interval rough boundaries to determine the weights of criteria}

BWM is a weight determining approach based on linear programming. It has received widespread attention in various fields (Pamučar et al., 2018; Liao et al., 2019b; Mi et al., 2019; Yazdani et al., 2019a). Motivated by the classical BWM and based on the interval rough boundaries, below we present an algorithm to obtain the weights of criteria.

Suppose that all experts select the best criterion and the worst criterion as $c_{B}$ and $c_{w}$. To obtain a comparison, each expert should determine the preference degree of the best criterion $c_{B}$ over criterion $c_{j}(j=1,2, \cdots, n)$ and criterion $c_{j}$ in relation to criterion $c_{w}$. The judgment of each pair takes the LTS $S_{(1)}=\left\{s_{0}=\right.$ equally important, $s_{1}=$ equally very important, $s_{2}=$ moderately imptorant, $s_{3}=$ moderately more imptorant, $s_{4}=$ strongly imp- torant, $s_{5}=$ strongly more imptorant, $s_{6}=$ very strongly more important, $s_{7}=$ extremely strong important, $s_{8}=$ extremely more important $\}$. Each expert's evaluation is expressed using HFLEs. Subsequently, the evaluation results of the Best-to-Others (BO) is obtained as $h_{s}^{(q) j w}(x)=\left\{s_{\varphi_{l}}(x) \mid s_{\varphi_{l}}(x) \in S_{(1)}, l=1, \ldots, L^{(q)}\right\}, q=1,2, \cdots, Q$ and the Others-to-Worst (OW) is obtained as the HFLEs $h_{s}^{(q) B j}(x)=\left\{S_{\varphi_{l}}(x) \mid s_{\varphi_{l}}(x) \in S_{(1)}, l=1, \ldots, L^{(q)}\right\}, q=1,2, \cdots, Q$.

Next, by the proposed probabilistic aggregation approach based on interval rough boundaries, the aggregated sequences on the preference of $c_{B}$ over $c_{j}$ can be expressed as the adjusted PLTS $h_{S}^{B j}\left(p^{*}\right)=\left\{s_{\varphi_{l}}^{B j}\left(p^{*\left(\varphi_{l}\right)}\right) \mid s_{\varphi_{l}}^{B j} \in S_{(1)}, l=1, \cdots, L_{B j}, \sum_{l=1}^{L_{B j}} p^{*\left(\varphi_{l}\right)}=1\right\}$ according to Eqs. (8)-(12). Similarly, the collective evaluations of all experts on the preference of $c_{j}$ over $c_{w}$ can be expressed as the adjusted PLTS $h_{S}^{j W}\left(p^{*}\right)=\left\{s_{\varphi_{l}}^{j W}\left(p_{l}{ }^{\left(\varphi_{l}\right)}\right) \mid s_{\varphi_{l}}^{j W} \in S_{(1)}, l=1, \cdots, L_{j W}, \sum_{l=1}^{L_{j W}} p^{*\left(\varphi_{l}\right)}=1\right\}$. Then, the $\mathrm{BO}$ vector and $\mathrm{OW}$ vector can be obtained as:

$$
A_{B O}=\left(E\left(h_{S}^{B 1}\left(p^{*}\right)\right), E\left(h_{S}^{B 2}\left(p^{*}\right)\right), \cdots, E\left(h_{S}^{B n}\left(p^{*}\right)\right)\right) ;
$$

$$
A_{O W}=\left(E\left(h_{S}^{1 W}\left(p^{*}\right)\right), E\left(h_{S}^{2 W}\left(p^{*}\right)\right), \cdots, E\left(h_{S}^{n W}\left(p^{*}\right)\right)\right),
$$

where: $E\left(h_{S}^{B j}\left(p^{\star}\right)\right)=\sum_{l=1}^{L_{B j}}\left(\varphi_{l}^{B j} \cdot p^{\star\left(\varphi_{l}\right)}\right)$ and $E\left(h_{S}^{j W}\left(p^{\star}\right)\right)=$ $\sum_{l=1}^{L_{j W}}\left(\varphi_{l}^{j W} \cdot p^{*\left(\varphi_{l}\right)}\right)$ are the expect values (Pang et al., 2016). Here, $\varphi_{l}^{B j}$ and $\varphi_{l}^{j W}$ are the subscripts of the PLTSs $h_{S}^{B j}\left(p^{*}\right)$ and $h_{S}^{j W}\left(p^{*}\right)$, respectively.

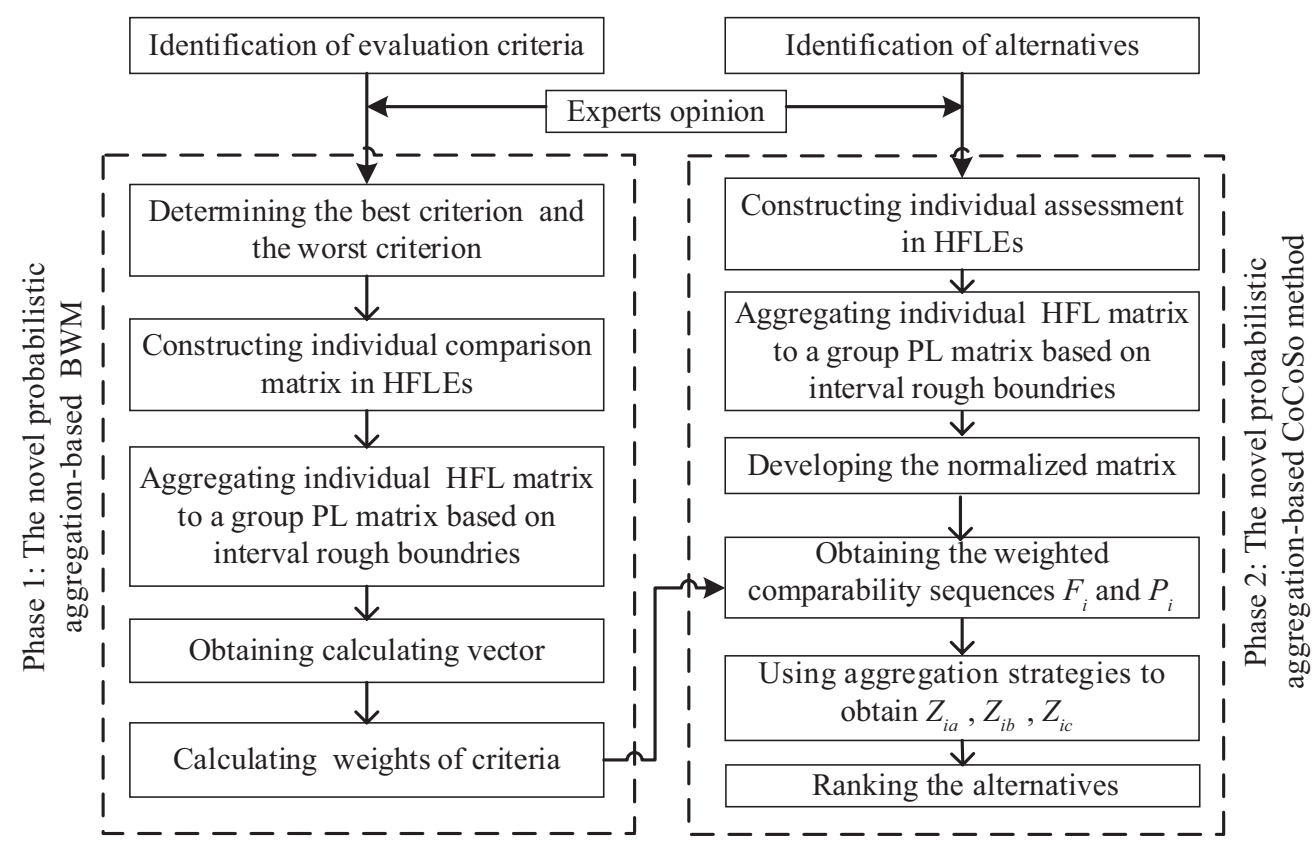

Figure 3. Framework of the proposed model 
On the basis of the linear model proposed by Rezaei (2016), Model 1 is constructed as follows:

$$
\begin{aligned}
& \text { Model } 1 \\
& \min \xi \\
& \text { s.t. } \\
& \left|\frac{w_{B}}{w_{j}}-E\left(h_{S}^{B j}\left(p^{*}\right)\right)\right| \leq \xi, \text { for all } j \\
& \left|\frac{w_{j}}{w_{W}}-E\left(h_{S}^{j W}\left(p^{*}\right)\right)\right| \leq \xi \text {, for all } j \\
& \sum_{j=1}^{n} w_{j}=1 \\
& w_{j} \geq 0, \text { for all } j
\end{aligned}
$$

Solving Model 1, we can obtain the optimal values of criteria weights $\left(w^{*}, w_{2}^{*}, \cdots, w_{j}^{*}, \cdots, w_{n}^{*}\right)^{T}$ and the corresponding minimum absolute difference $\xi^{*}$, based on which, we can check the consistency of the collective preferences $h_{S}^{B j}\left(p^{*}\right)$ and $h_{S}^{j W}\left(p^{*}\right)$. When $\xi^{*}=0$, the pairwise comparisons are supposed to be consistent. In this sense, $\xi^{\star}$ can be regarded as a consistency measure. For more detail about the consistency checking and repairing of the BWM, please refer to Rezaei (2015).

\subsection{A probabilistic aggregation-based CoCoSo method with interval rough boundaries}

The CoCoSo method has been utilized widely in applications. In the following, we develop an interval rough boundaries-based probabilistic aggregation CoCoSo method to rank alternatives.

To ensure the flexibility and objectivity of experts' judgments, the HFLEs are used to express experts' assessments of alternatives with a subscript-symmetric LTS $S_{(2)}=\left\{s_{\alpha} \mid \alpha=-\tau, \cdots,-1,0,1, \cdots, \tau\right\}$. Then, an HFL judgment matrix of expert $e_{q}$ can be constructed as:

$$
D^{(q)}=\left[\begin{array}{ccccc}
h_{S}^{11(q)} & \cdots & h_{S}^{1 j(q)} & \cdots & h_{S}^{1 n(q)} \\
\vdots & \ddots & \vdots & \ddots & \vdots \\
h_{S}^{i 1(q)} & \cdots & h_{S}^{i j(q)} & \cdots & h_{S}^{i n(q)} \\
\vdots & \ddots & \vdots & \ddots & \vdots \\
h_{S}^{m 1(q)} & \cdots & h_{S}^{m j}(q) & \cdots & h_{S}^{m n}(q)
\end{array}\right] .
$$

To express the group opinions completely, by Eqs. (8)(12), the individual opinions can be aggregated into a decision matrix $D=\left(h_{S}^{i j}\left(p^{\star}\right)\right)_{m \times n}$ through the probabilistic aggregation approach based on interval rough boundaries, which is expressed as:

$$
D=\left[\begin{array}{ccccc}
h_{S}^{11}\left(p^{*}\right) & \cdots & h_{S}^{1 j}\left(p^{*}\right) & \cdots & h_{S}^{1 n}\left(p^{\star}\right) \\
\vdots & \ddots & \vdots & \ddots & \vdots \\
h_{S}^{i 1}\left(p^{\star}\right) & \cdots & h_{S}^{i j}\left(p^{\star}\right) & \cdots & h_{S}^{i n}\left(p^{\star}\right) \\
\vdots & \ddots & \vdots & \ddots & \vdots \\
h_{S}^{m 1}\left(p^{\star}\right) & \cdots & h_{S}^{m j}\left(p^{*}\right) & \cdots & h_{S}^{m n}\left(p^{\star}\right)
\end{array}\right] .
$$

Next, we establish a normalized matrix based on the following compromise normalization equations: $y_{i j}=\frac{E\left(h_{S}^{i j}\left(p^{*}\right)-\min _{i} E\left(h_{S}^{i j}\left(p^{*}\right)\right.\right.}{\max _{i} E\left(h_{S}^{i j}\left(p^{\star}\right)-\min _{i} E\left(h_{S}^{i j}\left(p^{\star}\right)\right.\right.}$, for benefit criteria

$y_{i j}=\frac{\max _{i} E\left(h_{S}^{i j}\left(p^{\star}\right)-E\left(h_{S}^{i j}\left(p^{\star}\right)\right.\right.}{\max _{i} E\left(h_{S}^{i j}\left(p^{\star}\right)-\min _{i} E\left(h_{S}^{i j}\left(p^{*}\right)\right.\right.}$, for cost criteria

where: $E\left(h_{S}^{i j}\left(p^{*}\right)\right.$ is the expected value of $h_{S}^{i j}\left(p^{*}\right)=\left\{s_{\varphi_{l}}\left(p^{*\left(\varphi_{l}\right)}\right) \mid s_{\varphi_{l}} \in S_{(2)}, l=1,2, \cdots, L\right\}$ with

$$
E\left(h_{S}^{i j}\left(p^{\star}\right)=\sum_{l=1}^{L}\left(\frac{\varphi_{l}^{i j}+\tau_{2}}{2 \tau_{2}} \times p^{\star(\varphi l)}\right)\right.
$$

where: $\tau_{2}$ is the scale of the LTS $S_{(2)}$ and $\varphi_{l}^{i j}$ is the subscript of $h_{S}^{i j}\left(p^{*}\right)$ (Wu \& Liao, 2018).

Next, we compute the weighted average comparability sequences and weighted geometric comparability sequences for each alternative as $F_{i}$ and $P_{i}$, respectively, and obtain two weak rankings through these two weighted methods.

The weighted average operator is a complete compensatory aggregation method, through which the largest comprehensive value with respect to all criteria can be obtained, while the power aggregation operator is characterized by the incomplete compensation, through which the small values cannot be compensated by the large values completely (Liao \& Wu, 2020):

$$
\begin{aligned}
& F_{i}=\sum_{j=1}^{n}\left(w_{j} y_{i j}\right) ; \\
& P_{i}=\sum_{j=1}^{n}\left(y_{i j}\right)^{w_{j}},
\end{aligned}
$$

where: $w_{j}$ represents the weights of criteria calculated in Section 3.1.

Three appraisal score strategies are used to generate the moderate performances of alternatives, which are presented as:

$$
\begin{aligned}
Z_{i a} & =\frac{F_{i}+P_{i}}{\sum_{i=1}^{m}\left(F_{i}+P_{i}\right)} ; \\
Z_{i b}= & \frac{F_{i}}{\min _{i}}+\frac{P_{i}}{\min P_{i}} ; \\
Z_{i c}= & \frac{\lambda F_{i}+(1-\lambda)\left(P_{i}\right)}{\lambda \max _{i} F_{i}+(1-\lambda) \max _{i} P_{i}} .
\end{aligned}
$$

In Eq. (22), $\lambda$ is determined by the preference of an expert on the compensation of criteria values. If the expert considers that the poor performances of an alternative under some criteria can be completely compensated by the good performances of the alternative under other criteria, then $F_{i}$ should be assigned a big coefficient, namely, $\lambda>0.5$; if the expert believes that the good performances of an alternative under some 
criteria cannot fully compensate for the poor performances under other criteria, $P_{i}$ should be assigned a big coefficient, namely, $\lambda<0.5$ (Liao \& Wu, 2020).

The final ranking of alternatives is determined based on $Z_{i}$ in ascending order:

$$
Z_{i}=\left(Z_{i a} Z_{i b} Z_{i c}\right)^{1 / 3}+\left(Z_{i a}+Z_{i b}+Z_{i c}\right) / 3 \text {. }
$$

\section{Case study: application of the proposed model for supplier evaluation in housing development}

Selecting an appropriate construction component supplier for property developers has a vital role in the success for the implementation of the residential whole-decoration strategy. This section presents a case study about supplier selection for construction components in housing development. The proposed multi-expert MCDM method based on the probability aggregation approach with interval rough boundaries is applied to solve the case.

\subsection{Case description}

Company A is one of the largest and most comprehensive property developers in China. In 2009, the property developer announced its residential whole-decoration strategy, and so far, more than $80 \%$ of its residential products delivering to customers have been achieved in whole-decoration. To improve the quality of the delivered residential products and reduce the product fit-out cost through supply chain management, the management committee of the property developer conduct supplier decisions using MCDM methods in their first step of building component supply chain management. Integral kitchen cabinet is one of the most important fit-out components as its expense accounts high proportion in the overall fit-out spending and its important role in quality guarantee of residential products. Thus, this study takes the integral kitchen cabi- net supplier selection for the property developer as an example.

The proposed hybrid MCDM model is applied to select an optimal supplier from five construction component suppliers $\left\{A_{1}, A_{2}, A_{3}, A_{4}, A_{5}\right\}$. The decision-making group of A company consists of five members $\left\{e_{1}, e_{2}, e_{3}, e_{4}, e_{5}\right\}$ : the chief executive $e_{1}$, general manager $e_{2}$, contract management manager $e_{3}$, and two experts $e_{4}, e_{5}$ with a minimum of five-year-experience on supply chain management in construction companies. According to the literature review, the fundamental criteria, such as quality, cost, green development and enterprise capability are selected (Luo et al., 2016; Yin et al., 2017). Moreover, since the target company focuses on the long-term relationship with the selected supplier so as to deliver the residential products better, faster and smoother, the cooperation potentiality is defined as strategy related criteria (Lam et al., 2010). The weight of each expert is $\gamma=1 / 5$. 12 evaluation criteria $\left\{c_{1}, c_{2}, \cdots, c_{12}\right\}$ which are grouped into five clusters are presented in Table 2. Among these criteria, the product price, installation cost and environmental effect are cost criteria, while the others are benefit criteria, and this decision-making group agreed that $c_{3}$ is the best criteria, and $c_{11}$ is the worst one.

\subsection{Solving the case by the probabilistic aggregation-based CoCoSo method with interval rough boundaries}

\subsubsection{Determining criteria weights by the BWM with interval rough boundaries}

The proposed probabilistic aggregation-based BWM is used here to obtain the weights of criteria for the integral kitchen cabinet supplier selection. Based on the case information given in Section 4.1, each member of the decision-making group is invited to make pairwise comparisons in which the preferences of the criteria

Table 2. The criteria for evaluation over candidate integral kitchen cabinet suppliers

\begin{tabular}{|c|c|c|c|}
\hline Criterion & Sub-criterion & Form & Target value \\
\hline \multirow[t]{3}{*}{ Quality } & Product sample pass rate $\left(c_{1}\right)$ & Benefit & $\max$ \\
\hline & Level of after-sale service $\left(c_{2}\right)$ & Benefit & $\max$ \\
\hline & Product performance $\left(c_{3}\right)$ & Benefit & $\max$ \\
\hline \multirow[t]{2}{*}{ Cost } & Product price $\left(\mathrm{c}_{4}\right)$ & Cost & $\min$ \\
\hline & Installation cost $\left(c_{5}\right)$ & Cost & $\min$ \\
\hline \multirow[t]{2}{*}{ Green development } & Environmental level $\left(\mathrm{c}_{6}\right)$ & Benefit & $\max$ \\
\hline & Environmental effect $\left(c_{7}\right)$ & Cost & $\min$ \\
\hline \multirow[t]{3}{*}{ Enterprise capability } & Innovation capability $\left(c_{8}\right)$ & Benefit & $\max$ \\
\hline & Professional skill $\left(c_{9}\right)$ & Benefit & $\max$ \\
\hline & Market position $\left(\mathrm{c}_{10}\right)$ & Benefit & $\max$ \\
\hline \multirow[t]{2}{*}{ Cooperation potentiality } & Cooperation intention $\left(c_{11}\right)$ & Benefit & $\max$ \\
\hline & Supply capability of emergency demand $\left(c_{12}\right)$ & Benefit & $\max$ \\
\hline
\end{tabular}


$c_{B}$ and $c_{w}$ were considered over the remaining criteria from the defined set. The evaluations were represented by HFLEs with the LTS $S_{(1)}$, which are shown as follows:

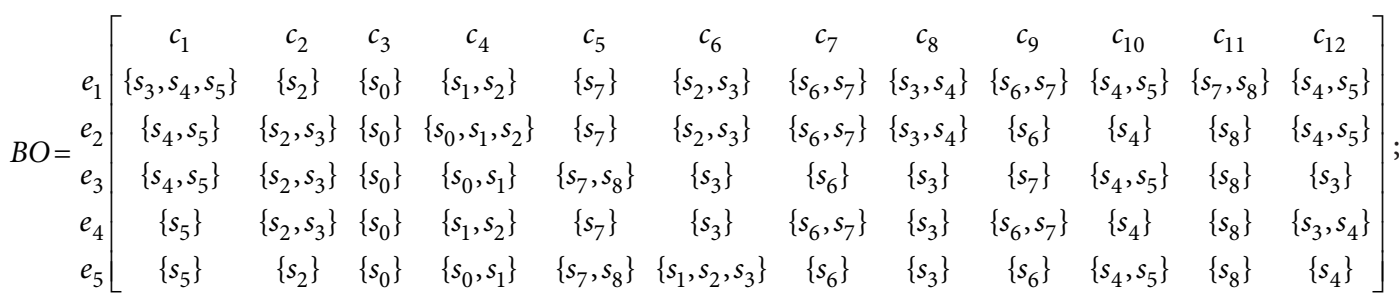

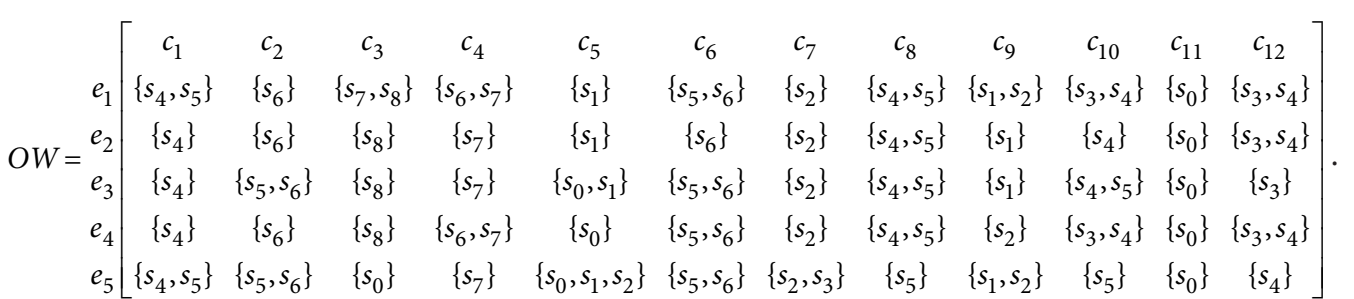

Then, we aggregate the preferences of the decisionmaking group on $c_{B}$ over $c_{j}$ to PLTSs $\left\{h_{S}^{B j}\left(p^{*}\right)\right\}_{1 \times 12}$ and $c_{j}$ over $c_{w}$ to PLTSs $\left\{h_{S}^{j W}\left(p^{\star}\right)\right\}_{1 \times 12}$ by Eqs. (8)-(12). The results are shown as:

$$
\begin{aligned}
& \left\{h_{S}^{B j}\left(p^{*}\right)\right\}_{1 \times 12}=\left\{\begin{array}{cccc}
c_{1} & c_{2} & c_{3} & c_{4} \\
\left\{s_{3}(0.12), s_{4}(0.30), s_{5}(0.59)\right\} & \left\{s_{2}(0.66), s_{3}(0.34)\right\} & \left\{s_{0}(1)\right\} & \left\{s_{0}(0.28), s_{1}(0.43), s_{2}(0.28)\right\} \\
c_{5} & c_{6} & c_{7} & c_{8} \\
\left\{s_{7}(0.76), s_{8}(0.24)\right\} & \left\{s_{2}(0.34), s_{3}(0.66)\right\} & \left\{s_{6}(0.66), s_{7}(0.34)\right\} & \left\{s_{3}(0.76), s_{4}(0.24)\right\} \\
c_{9} & c_{10} & c_{11} & c_{12} \\
\left\{s_{6}(0.59), s_{7}(0.41)\right\} & \left\{s_{4}(0.66), s_{5}(0.34)\right\} & \left\{s_{7}(0.13), s_{8}(0.87)\right\} & \left\{s_{3}(0.29), s_{4}(0.47), s_{5}(0.24)\right\}
\end{array}\right\} ; \\
& \left\{h_{S}^{j w}\left(p^{\star}\right)\right\}_{1 \times 12}=\left\{\begin{array}{cccc}
c_{1} & c_{2} & c_{3} & c_{4} \\
\left\{s_{4}(0.76), s_{5}(0.24)\right\} & \left\{s_{5}(0.24), s_{6}(0.76)\right\} & \left\{s_{7}(0.13), s_{8}(0.87)\right\} & \left\{s_{6}(0.24), s_{7}(0.76)\right\} \\
c_{5} & c_{6} & c_{7} & c_{8} \\
\left\{s_{0}(0.22), s_{1}(0.66), s_{2}(0.12)\right\} & \left\{s_{5}(0.42), s_{6}(0.58)\right\} & \left\{s_{2}(0.87), s_{3}(0.13)\right\} & \left\{s_{4}(0.42), s_{5}(0.58)\right\} \\
c_{9} & c_{10} & c_{11} & c_{12} \\
\left\{s_{1}(0.59), s_{2}(0.41)\right\} & \left\{s_{3}(0.24), s_{4}(0.62), s_{5}(0.15)\right\} & \left\{s_{0}(1)\right\} & \left\{s_{3}(0.5), s_{4}(0.5)\right\}
\end{array}\right\} .
\end{aligned}
$$

By Eqs. (13) and (14), the BO vector and the OW vector are obtained as:

$A_{B O}=(4.47,2.34,0.00,1.00,7.24,2.66,6.34,3.24,6.41,4.34,7.87,3.95)$;

$A_{W O}=(4.24,5.76,7.87,6.76,0.90,5.58,2.13,4.58,1.41,3.91,0.00,3.50)$.

Then, according to Model 1 in Section 3.1, the optimal weight vector can be obtained as:

$$
\begin{aligned}
& w^{*}=(0.066,0.102,0.208,0.131,0.035,0.096,0.041,0.108, \\
& 0.041,0.069,0.023,0.08)^{T} .
\end{aligned}
$$

\subsubsection{Ranking the suppliers by the probabilistic aggregation-based CoCoSo method}

Once the weights of criteria are determined, the probabilistic aggregation-based CoCoSo method is applied to evaluate the integral kitchen cabinet suppliers. The evaluations were carried out by the decision-making group with the predefined evaluation criteria in Table 2 . The judgments of each member take the LTS $S_{(2)}=\left\{s_{-3}=\right.$ very bad, $s_{-2}=$ bad, $s_{-1}=$ somewhat bad, $s_{0}=$ normal, $s_{1}=$ somewhat good, $s_{2}=$ good, $s_{3}=$ very good $\}$. The HFL judgments for each expert are shown in Table 3.

Next, we aggregate all individuals' evaluations to group opinions expressed as PLTSs by Eqs. (8)-(12). The results are shown in Table 4.

Afterwards, based on the decision-making matrix, the expected values of the suppliers and the normalized supplier matrix can be obtained by Eqs. (15)-(17), shown in Tables 5 and 6. Then, two aggregation models are computed by Eqs. (18) and (19), and the weak ranking of the suppliers is acquired, listed in Tables 7 and 8.

The values of $Z_{i a}, Z_{i b}$ and $Z_{i c}$ are derived by Eqs. (20)(22). Here, we suppose that the preference of the decision maker on the criteria compensation is neutral, that is to say, $\lambda=0.5$. Finally, we calculate the values of $Z_{i}$ by Eq. (23) for each supplier, which yields the comprehensive performance scores for suppliers. Based on these scores, we can determine the priorities of the suppliers, which are listed in Table 9. 
Table 3. Individual evaluations of the suppliers

\begin{tabular}{|c|c|c|c|c|c|c|c|c|c|c|c|c|c|}
\hline Alter. & & $c_{1}$ & $c_{2}$ & $c_{3}$ & $c_{4}$ & $c_{5}$ & $c_{6}$ & $c_{7}$ & $c_{8}$ & $c_{9}$ & $c_{10}$ & $c_{11}$ & $c_{12}$ \\
\hline \multirow{5}{*}{$A_{1}$} & $e_{1}$ & $\left\{s_{2}, s_{3}\right\}$ & $\left\{s_{1}, s_{2}\right\}$ & $\left\{s_{2}\right\}$ & $\left\{s_{1}, s_{2}\right\}$ & $\left\{s_{1}\right\}$ & $\left\{s_{-1}\right\}$ & $\left\{s_{-1}, s_{0}\right\}$ & $\left\{s_{-1}, s_{0}\right\}$ & $\left\{s_{1}, s_{2}\right\}$ & $\left\{s_{2}\right\}$ & $\left\{s_{-1}, s_{0}\right\}$ & $\left\{s_{2}, s_{3}\right\}$ \\
\hline & $e_{2}$ & $\left\{s_{1}, s_{2}, s_{3}\right\}$ & $\left\{s_{2}\right\}$ & $\left\{s_{1}, s_{2}\right\}$ & $\left\{s_{2}\right\}$ & $\left\{s_{1}\right\}$ & $\left\{s_{-1}\right\}$ & $\left\{s_{0}\right\}$ & $\left\{s_{-1}\right\}$ & $\left\{s_{2}\right\}$ & $\left\{s_{1}, s_{2}\right\}$ & $\left\{s_{0}\right\}$ & $\left\{s_{2}, s_{3}\right\}$ \\
\hline & $e_{3}$ & $\left\{s_{0}, s_{1}\right\}$ & $\left\{s_{1}, s_{2}\right\}$ & $\left\{s_{2}\right\}$ & $\left\{s_{1}, s_{2}\right\}$ & $\left\{s_{1}\right\}$ & $\left\{s_{-1}, s_{0}\right\}$ & $\left\{s_{-1}, s_{0}\right\}$ & $\left\{s_{-1}\right\}$ & $\left\{s_{1}\right\}$ & $\left\{s_{1}, s_{2}\right\}$ & $\left\{s_{0}\right\}$ & $\left\{s_{2}\right\}$ \\
\hline & $e_{4}$ & $\left\{s_{2}, s_{3}\right\}$ & $\left\{s_{2}\right\}$ & $\left\{s_{2}\right\}$ & $\left\{s_{2}\right\}$ & $\left\{s_{1}\right\}$ & $\left\{s_{-1}\right\}$ & $\left\{s_{-1}\right\}$ & $\left\{s_{-1}\right\}$ & $\left\{s_{1}, s_{2}\right\}$ & $\left\{s_{2}\right\}$ & $\left\{s_{-1}, s_{0}\right\}$ & $\left\{s_{2}, s_{3}\right\}$ \\
\hline & $e_{5}$ & $\left\{s_{0}, s_{1}\right\}$ & $\left\{s_{1}, s_{2}\right\}$ & $\left\{s_{1}, s_{2}\right\}$ & $\left\{s_{2}\right\}$ & $\left\{s_{1}\right\}$ & $\left\{s_{-1}, s_{0}\right\}$ & $\left\{s_{-1}, s_{0}\right\}$ & $\left\{s_{-1}\right\}$ & $\left\{s_{1}\right\}$ & $\left\{s_{1}, s_{2}\right\}$ & $\left\{s_{-1}, s_{0}\right\}$ & $\left\{s_{2}\right\}$ \\
\hline \multirow{5}{*}{$A_{2}$} & $e_{1}$ & $\left\{s_{0}, s_{1}\right\}$ & $\left\{s_{2}\right\}$ & $\left\{s_{0}, s_{1}\right\}$ & $\left\{s_{1}, s_{2}\right\}$ & $\left\{s_{-2}, s_{-1}\right\}$ & $\left\{s_{1}, s_{2}\right\}$ & $\left\{s_{0}, s_{1}\right\}$ & $\left\{s_{1}, s_{2}\right\}$ & $\left\{s_{2}\right\}$ & $\left\{s_{1}, s_{2}\right\}$ & $\left\{s_{1}\right\}$ & $\left\{s_{2}, s_{3}\right\}$ \\
\hline & $e_{2}$ & $\left\{s_{1}\right\}$ & $\left\{s_{2}\right\}$ & $\left\{s_{0}, s_{1}\right\}$ & $\left\{s_{1}\right\}$ & $\left\{s_{-1}\right\}$ & $\left\{s_{2}\right\}$ & $\left\{s_{0}, s_{1}\right\}$ & $\left\{s_{1}\right\}$ & $\left\{s_{1}\right\}$ & $\left\{s_{2}\right\}$ & $\left\{s_{1}\right\}$ & $\left\{s_{2}, s_{3}\right\}$ \\
\hline & $e_{3}$ & $\left\{s_{1}\right\}$ & $\left\{s_{2}\right\}$ & $\left\{s_{0}, s_{1}\right\}$ & $\left\{s_{1}\right\}$ & $\left\{s_{-1}\right\}$ & $\left\{s_{2}\right\}$ & $\left\{s_{0}, s_{1}\right\}$ & $\left\{s_{1}, s_{2}\right\}$ & $\left\{s_{1}\right\}$ & $\left\{s_{1}, s_{2}\right\}$ & $\left\{s_{0}, s_{1}\right\}$ & $\left\{s_{2}\right\}$ \\
\hline & $e_{4}$ & $\left\{s_{0}, s_{1}\right\}$ & $\left\{s_{2}\right\}$ & $\left\{s_{0}\right\}$ & $\left\{s_{1}, s_{2}\right\}$ & $\left\{s_{-2}, s_{-1}\right\}$ & $\left\{s_{2}\right\}$ & $\left\{s_{0}, s_{1}\right\}$ & $\left\{s_{1}\right\}$ & $\left\{s_{2}\right\}$ & $\left\{s_{1}, s_{2}\right\}$ & $\left\{s_{1}\right\}$ & $\left\{s_{2}, s_{3}\right\}$ \\
\hline & $e_{5}$ & $\left\{s_{1}\right\}$ & $\left\{s_{2}\right\}$ & $\left\{s_{0}, s_{1}\right\}$ & $\left\{s_{1}\right\}$ & $\left\{s_{-1}\right\}$ & $\left\{s_{1}, s_{2}\right\}$ & $\left\{s_{0}, s_{1}, s_{2}\right\}$ & $\left\{s_{1}, s_{2}\right\}$ & $\left\{s_{0}, s_{1}, s_{2}\right\}$ & $\left\{s_{1}\right\}$ & $\left\{s_{1}\right\}$ & $\left\{s_{2}\right\}$ \\
\hline \multirow{5}{*}{$A_{3}$} & $e_{1}$ & $\left\{s_{1}, s_{2}\right\}$ & $\left\{s_{-1}\right\}$ & $\left\{s_{2}\right\}$ & $\left\{s_{1}\right\}$ & $\left\{s_{0}\right\}$ & $\left\{s_{1}, s_{2}\right\}$ & $\left\{s_{-1}, s_{0}\right\}$ & $\left\{s_{-1}\right\}$ & $\left\{s_{1}, s_{2}\right\}$ & $\left\{s_{1}\right\}$ & $\left\{s_{0}, s_{1}\right\}$ & $\left\{s_{1}\right\}$ \\
\hline & $e_{2}$ & $\left\{s_{1}, s_{2}\right\}$ & $\left\{s_{-1}, s_{0}\right\}$ & $\left\{s_{1}, s_{2}\right\}$ & $\left\{s_{1}, s_{2}\right\}$ & $\left\{s_{0}\right\}$ & $\left\{s_{1}, s_{2}\right\}$ & $\left\{s_{-1}, s_{0}\right\}$ & $\left\{s_{-1}, s_{0}\right\}$ & $\left\{s_{2}\right\}$ & $\left\{s_{1}\right\}$ & $\left\{s_{0}, s_{1}\right\}$ & $\left\{s_{1}\right\}$ \\
\hline & $e_{3}$ & $\left\{s_{2}\right\}$ & $\left\{s_{0}\right\}$ & $\left\{s_{1}, s_{2}\right\}$ & $\left\{s_{0}, s_{1}\right\}$ & $\left\{s_{0}\right\}$ & $\left\{s_{1}\right\}$ & $\left\{s_{0}\right\}$ & $\left\{s_{-1}, s_{0}\right\}$ & $\left\{s_{1}, s_{2}\right\}$ & $\left\{s_{0}\right\}$ & $\left\{s_{0}, s_{1}\right\}$ & $\left\{s_{1}, s_{2}\right\}$ \\
\hline & $e_{4}$ & $\left\{s_{2}\right\}$ & $\left\{s_{-1}\right\}$ & $\left\{s_{1}\right\}$ & $\left\{s_{2}\right\}$ & $\left\{s_{1}\right\}$ & $\left\{s_{2}\right\}$ & $\left\{s_{-1}\right\}$ & $\left\{s_{0}\right\}$ & $\left\{s_{2}\right\}$ & $\left\{s_{1}\right\}$ & $\left\{s_{0}, s_{1}\right\}$ & $\left\{s_{1}\right\}$ \\
\hline & $e_{5}$ & $\left\{s_{1}, s_{2}\right\}$ & $\left\{s_{-1}, s_{0}\right\}$ & $\left\{s_{1}\right\}$ & $\left\{s_{1}\right\}$ & $\left\{s_{1}\right\}$ & $\left\{s_{1}, s_{2}\right\}$ & $\left\{s_{-1}, s_{0}\right\}$ & $\left\{s_{-1}, s_{0}\right\}$ & $\left\{s_{1}, s_{2}\right\}$ & $\left\{s_{0}\right\}$ & $\left\{s_{1}\right\}$ & $\left\{s_{2}\right\}$ \\
\hline \multirow{5}{*}{$A_{4}$} & $e_{1}$ & $\left\{s_{1}, s_{2}\right\}$ & & & $\left\{s_{1}\right\}$ & $\left\{s_{0}\right\}$ & $\left\{s_{1}, s_{2}\right\}$ & $\left\{s_{-2}, s_{-1}\right\}$ & $\left\{s_{1}, s_{2}\right\}$ & $\left\{s_{1}, s_{2}\right\}$ & $\left\{s_{2}\right\}$ & $\left\{s_{-1}\right\}$ & $\left\{s_{1}, s_{2}\right\}$ \\
\hline & $e_{2}$ & $\left\{s_{1}, s_{2}\right\}$ & $\left\{s_{1}, s_{2}\right\}$ & $\left\{s_{0}\right\}$ & $\left\{s_{1}\right\}$ & $\left\{s_{0}\right\}$ & $\left\{s_{1}, s_{2}\right\}$ & $\left\{s_{-2}, s_{-1}\right\}$ & $\left\{s_{1}, s_{2}\right\}$ & $\left\{s_{1}\right\}$ & $\left\{s_{2}\right\}$ & $\left\{s_{-1}, s_{0}\right\}$ & $\left\{s_{2}\right\}$ \\
\hline & $e_{3}$ & $\left\{s_{2}\right\}$ & $\left\{s_{2}\right\}$ & $\left\{s_{-1}, s_{0}\right\}$ & $\left\{s_{1}\right\}$ & $\left\{s_{0}\right\}$ & $\left\{s_{2}\right\}$ & $\left\{s_{-1}\right\}$ & $\left\{s_{2}\right\}$ & $\left\{s_{1}, s_{2}\right\}$ & $\left\{s_{1}, s_{2}\right\}$ & $\left\{s_{0}\right\}$ & $\left\{s_{1}, s_{2}\right\}$ \\
\hline & $e_{4}$ & $\left\{s_{1}, s_{2}\right\}$ & $\left\{s_{2}\right\}$ & $\left\{s_{0}, s_{1}\right\}$ & $\left\{s_{1}\right\}$ & $\left\{s_{-1}, s_{0}\right\}$ & $\left\{s_{2}\right\}$ & $\left\{s_{-2}\right\}$ & $\left\{s_{2}\right\}$ & $\left\{s_{1}, s_{2}\right\}$ & $\left\{s_{2}\right\}$ & $\left\{s_{-1}\right\}$ & $\left\{s_{1}, s_{2}\right\}$ \\
\hline & $e_{5}$ & $\left\{s_{1}, s_{2}\right\}$ & $\left\{s_{2}\right\}$ & $\left\{s_{0}\right\}$ & $\left\{s_{1}\right\}$ & $\left\{s_{0}\right\}$ & $\left\{s_{2}\right\}$ & $\left\{s_{-2}, s_{-1}, s_{0}\right\}$ & $\left\{s_{2}\right\}$ & $\left\{s_{0}, s_{1}, s_{2}\right\}$ & $\left\{s_{1}, s_{2}\right\}$ & $\left\{s_{-1}, s_{0}\right\}$ & $\left\{s_{2}\right\}$ \\
\hline \multirow{5}{*}{$A_{5}$} & $e_{1}$ & $\left\{s_{1}, s_{2}\right\}$ & $\left\{s_{-1}, s_{0}\right\}$ & $\left\{s_{0}\right\}$ & $\left\{s_{1}, s_{2}\right\}$ & $\left\{s_{-2}, s_{-1}\right\}$ & $\left\{s_{1}, s_{2}\right\}$ & $\left\{s_{0}, s_{1}\right\}$ & $\left\{s_{1}, s_{2}\right\}$ & $\left\{s_{1}, s_{2}\right\}$ & $\left\{s_{2}\right\}$ & $\left\{s_{1}, s_{2}\right\}$ & $\left\{s_{2}, s_{3}\right\}$ \\
\hline & $e_{2}$ & $\left\{s_{1}\right\}$ & $\left\{s_{-1}, s_{0}\right\}$ & $\left\{s_{0}, s_{1}\right\}$ & $\left\{s_{2}\right\}$ & $\left\{s_{-1}\right\}$ & $\left\{s_{1}, s_{2}\right\}$ & $\left\{s_{0}, s_{1}\right\}$ & $\left\{s_{1}, s_{2}\right\}$ & $\left\{s_{1}, s_{2}\right\}$ & $\left\{s_{1}\right\}$ & $\left\{s_{0}, s_{1}\right\}$ & $\left\{s_{2}\right\}$ \\
\hline & $e_{3}$ & $\left\{s_{1}\right\}$ & $\left\{s_{-1}, s_{0}\right\}$ & $\left\{s_{0}, s_{1}\right\}$ & $\left\{s_{1}, s_{2}\right\}$ & $\left\{s_{-1}\right\}$ & $\left\{s_{2}\right\}$ & $\left\{s_{1}\right\}$ & $\left\{s_{2}\right\}$ & $\left\{s_{1}, s_{2}\right\}$ & $\left\{s_{1}\right\}$ & $\left\{s_{1}, s_{2}\right\}$ & $\left\{s_{2}, s_{3}\right\}$ \\
\hline & $e_{4}$ & $\left\{s_{1}, s_{2}\right\}$ & $\left\{s_{0}\right\}$ & $\left\{s_{0}\right\}$ & $\left\{s_{2}\right\}$ & $\left\{s_{-2}, s_{-1}\right\}$ & $\left\{s_{1}, s_{2}\right\}$ & $\left\{s_{1}\right\}$ & $\left\{s_{2}\right\}$ & $\left\{s_{1}, s_{2}, s_{3}\right\}$ & $\left\{s_{2}\right\}$ & $\left\{s_{0}, s_{1}\right\}$ & $\left\{s_{2}\right\}$ \\
\hline & $e_{5}$ & $\left\{s_{1}\right\}$ & $\left\{s_{-1}, s_{0}\right\}$ & $\left\{s_{1}\right\}$ & $\left\{s_{1}\right\}$ & $\left\{s_{-1}\right\}$ & $\left\{s_{2}\right\}$ & $\left\{s_{0}, s_{1}\right\}$ & $\left\{s_{1}, s_{2}\right\}$ & $\left\{s_{1}, s_{2}\right\}$ & $\left\{s_{1}, s_{2}\right\}$ & $\left\{s_{1}, s_{2}\right\}$ & $\left\{s_{2}\right\}$ \\
\hline
\end{tabular}

Table 4. The collective decision-making matrix

\begin{tabular}{|c|c|c|c|c|c|c|}
\hline Alter. & $c_{1}$ & $c_{2}$ & $c_{3}$ & $c_{4}$ & $c_{5}$ & $c_{6}$ \\
\hline$A_{1}$ & $\begin{array}{l}\left\{s_{0}(0.21), s_{1}(0.26),\right. \\
\left.s_{2}(0.26), s_{3}(0.27)\right\}\end{array}$ & $\left\{s_{1}(0.34), s_{2}(0.66)\right\}$ & $\left\{s_{1}(0.24), s_{2}(0.76)\right\}$ & $\left\{s_{1}(0.24), s_{2}(0.76)\right\}$ & $\left\{s_{1}(1)\right\}$ & $\left\{s_{-1}(0.76), s_{0}(0.24)\right\}$ \\
\hline$A_{2}$ & $\left\{s_{0}(0.34), s_{1}(0.66)\right\}$ & $\left\{s_{2}(1)\right\}$ & $\left\{s_{0}(0.58), s_{1}(0.42)\right\}$ & $\left\{s_{1}(0.76), s_{2}(0.24)\right\}$ & $\left\{s_{-2}(0.24), s_{-1}(0.76)\right\}$ & $\left\{s_{1}(0.24), s_{2}(0.76)\right\}$ \\
\hline$A_{3}$ & $\left\{s_{1}(0.42), s_{2}(0.58)\right\}$ & $\left\{s_{-1}(0.5), s_{0}(0.5)\right\}$ & $\left\{s_{1}(0.59), s_{2}(0.41)\right\}$ & $\begin{array}{c}\left\{s_{0}(0.15), s_{1}(0.54)\right. \\
\left.s_{2}(0.3)\right\}\end{array}$ & $\left\{s_{0}(0.6), s_{1}(0.4)\right\}$ & $\left\{s_{1}(0.5), s_{2}(0.5)\right\}$ \\
\hline$A_{4}$ & $\left\{s_{1}(0.42), s_{2}(0.58)\right\}$ & $\left\{s_{1}(0.24), s_{2}(0.76)\right\}$ & $\begin{array}{c}\left\{s_{-1}(0.14), s_{0}(0.71)\right. \\
\left.s_{1}(0.14)\right\}\end{array}$ & $\left\{s_{1}(1)\right\}$ & $\left\{s_{-1}(0.13), s 0(0.87)\right\}$ & $\left\{s_{1}(0.24), s_{2}(0.76)\right\}$ \\
\hline$A_{5}$ & $\left\{s_{1}(0.76), s_{2}(0.24)\right\}$ & $\left\{s_{-1}(0.42), s_{0}(0.58)\right\}$ & $\left\{s_{0}(0.59), s_{1}(0.41)\right\}$ & $\left\{s_{1}(0.32), s_{2}(0.68)\right\}$ & $\left\{s_{-2}(0.24), s_{-1}(0.76)\right\}$ & $\left\{s_{1}(0.34), s_{2}(0.66)\right\}$ \\
\hline Alter. & $c_{7}$ & $c_{8}$ & $c_{9}$ & $c_{10}$ & $c_{11}$ & $c_{12}$ \\
\hline$A_{1}$ & $\left\{s_{-1}(0.5), s_{0}(0.5)\right\}$ & $\left\{s_{-1}(0.87), s_{0}(0.13)\right\}$ & $\left\{s_{1}(0.59), s_{2}(0.41)\right\}$ & $\left\{s_{1}(0.34), s_{2}(0.66)\right\}$ & $\left\{s_{-1}(0.34), s_{0}(0.66)\right\}$ & $\left\{s_{2}(0.66), s_{3}(0.34)\right\}$ \\
\hline$A_{2}$ & $\left\{s_{0}(0.51), s_{1}(0.49)\right\}$ & $\left\{s_{1}(0.66), s_{2}(0.34)\right\}$ & $\begin{array}{c}\left\{s_{0}(0.12), s_{1}(0.43)\right. \\
\left.s_{2}(0.44)\right\}\end{array}$ & $\left\{s_{1}(0.5), s 2(0.5)\right\}$ & $\left\{s_{0}(0.13), s_{1}(0.87)\right\}$ & $\left\{s_{2}(0.66), s_{3}(0.34)\right\}$ \\
\hline$A_{3}$ & $\left\{s_{-1}(0.5), s 0(0.5)\right\}$ & $\left\{s_{-1}(0.5), s_{0}(0.5)\right\}$ & $\left\{s_{1}(0.34), s_{2}(0.66)\right\}$ & $\left\{s_{0}(0.4), s_{1}(0.6)\right\}$ & $\left\{s_{0}(0.42), s_{1}(0.58)\right\}$ & $\left\{s_{1}(0.68), s_{2}(0.32)\right\}$ \\
\hline$A_{4}$ & $\begin{array}{c}\left\{s_{-2}(0.45), s_{-1}(0.44)\right. \\
\left.s_{0}(0.12)\right\}\end{array}$ & $\left\{s_{1}(0.24), s_{2}(0.76)\right\}$ & $\begin{array}{c}\left\{s_{0}(0.12), s_{1}(0.5)\right. \\
\left.s_{2}(0.38)\right\}\end{array}$ & $\left\{s_{1}(0.24), s_{2}(0.76)\right\}$ & $\left\{s_{-1}(0.59), s_{0}(0.41)\right\}$ & $\left\{s_{1}(0.34), s_{2}(0.66)\right\}$ \\
\hline$A_{5}$ & $\left\{s_{0}(0.34), s_{1}(0.66)\right\}$ & $\left\{s_{1}(0.34), s_{2}(0.66)\right\}$ & $\begin{array}{c}\left\{s_{1}(0.45), s_{2}(0.44)\right. \\
\left.s_{3}(0.12)\right\}\end{array}$ & $\left\{s_{1}(0.5), s_{2}(0.5)\right\}$ & $\begin{array}{c}\left\{s_{0}(0.23), s_{1}(0.46),\right. \\
\left.s_{2}(0.31)\right\}\end{array}$ & $\left\{s_{2}(0.76), s_{3}(0.24)\right\}$ \\
\hline
\end{tabular}


Table 5. The expected values of the suppliers

\begin{tabular}{|c|c|c|c|c|c|c|c|c|c|c|c|c|}
\hline Supplier & $c_{1}$ & $c_{2}$ & $c_{3}$ & $c_{4}$ & $c_{5}$ & $c_{6}$ & $c_{7}$ & $c_{8}$ & $c_{9}$ & $c_{10}$ & $c_{11}$ & $c_{12}$ \\
\hline$A_{1}$ & 0.764 & 0.777 & 0.793 & 0.793 & 0.667 & 0.373 & 0.417 & 0.355 & 0.736 & 0.777 & 0.444 & 0.889 \\
\hline$A_{2}$ & 0.627 & 0.833 & 0.570 & 0.707 & 0.293 & 0.753 & 0.582 & 0.723 & 0.720 & 0.750 & 0.645 & 0.889 \\
\hline$A_{3}$ & 0.777 & 0.417 & 0.736 & 0.692 & 0.567 & 0.667 & 0.417 & 0.417 & 0.777 & 0.600 & 0.596 & 0.719 \\
\hline$A_{4}$ & 0.763 & 0.793 & 0.500 & 0.667 & 0.478 & 0.753 & 0.279 & 0.793 & 0.710 & 0.793 & 0.402 & 0.777 \\
\hline$A_{5}$ & 0.707 & 0.430 & 0.569 & 0.781 & 0.293 & 0.721 & 0.611 & 0.777 & 0.778 & 0.750 & 0.680 & 0.873 \\
\hline
\end{tabular}

Table 6. The normalized decision matrix

\begin{tabular}{|c|c|c|c|c|c|c|c|c|c|c|c|c|}
\hline Supplier & $c_{1}$ & $c_{2}$ & $c_{3}$ & $c_{4}$ & $c_{5}$ & $c_{6}$ & $c_{7}$ & $c_{8}$ & $c_{9}$ & $c_{10}$ & $c_{11}$ & $c_{12}$ \\
\hline$A_{1}$ & 0.912 & 0.865 & 1.000 & 0.000 & 0.000 & 0.000 & 0.585 & 0.000 & 0.378 & 0.917 & 0.150 & 1.000 \\
\hline$A_{2}$ & 0.000 & 1.000 & 0.240 & 0.684 & 1.000 & 1.000 & 0.085 & 0.839 & 0.143 & 0.776 & 0.874 & 1.000 \\
\hline$A_{3}$ & 1.000 & 0.000 & 0.804 & 0.800 & 0.268 & 0.772 & 0.585 & 0.141 & 0.989 & 0.000 & 0.698 & 0.000 \\
\hline$A_{4}$ & 0.905 & 0.904 & 0.000 & 1.000 & 0.504 & 1.000 & 1.000 & 1.000 & 0.000 & 1.000 & 0.000 & 0.340 \\
\hline$A_{5}$ & 0.532 & 0.031 & 0.235 & 0.100 & 1.000 & 0.916 & 0.000 & 0.963 & 1.000 & 0.776 & 1.000 & 0.906 \\
\hline
\end{tabular}

Table 7. The weighted average comparability sequence and the corresponding ranking results of the suppliers

\begin{tabular}{|c|c|c|c|c|c|c|c|c|c|c|c|c|c|c|}
\hline Supplier & $c_{1}$ & $c_{2}$ & $c_{3}$ & $c_{4}$ & $c_{5}$ & $c_{6}$ & $c_{7}$ & $c_{8}$ & $c_{9}$ & $c_{10}$ & $c_{11}$ & $c_{12}$ & $F_{i}$ & Ranking \\
\hline$A_{1}$ & 0.060 & 0.088 & 0.208 & 0.000 & 0.000 & 0.000 & 0.024 & 0.000 & 0.015 & 0.063 & 0.003 & 0.080 & 0.543 & 3 \\
\hline$A_{2}$ & 0.000 & 0.102 & 0.050 & 0.090 & 0.035 & 0.096 & 0.003 & 0.091 & 0.006 & 0.054 & 0.020 & 0.080 & 0.626 & 2 \\
\hline$A_{3}$ & 0.066 & 0.000 & 0.167 & 0.105 & 0.009 & 0.074 & 0.024 & 0.015 & 0.041 & 0.000 & 0.016 & 0.000 & 0.517 & 5 \\
\hline$A_{4}$ & 0.060 & 0.092 & 0.000 & 0.131 & 0.018 & 0.096 & 0.041 & 0.108 & 0.000 & 0.069 & 0.000 & 0.027 & 0.642 & 1 \\
\hline$A_{5}$ & 0.035 & 0.003 & 0.049 & 0.013 & 0.035 & 0.088 & 0.000 & 0.104 & 0.041 & 0.054 & 0.023 & 0.072 & 0.517 & 4 \\
\hline
\end{tabular}

Table 8. The weighted geometric comparability sequence and the corresponding ranking results of the suppliers

\begin{tabular}{|c|c|c|c|c|c|c|c|c|c|c|c|c|c|c|}
\hline Supplier & $c_{1}$ & $c_{2}$ & $c_{3}$ & $c_{4}$ & $c_{5}$ & $c_{6}$ & $c_{7}$ & $c_{8}$ & $c_{9}$ & $c_{10}$ & $c_{11}$ & $c_{12}$ & $P_{i}$ & Ranking \\
\hline$A_{1}$ & 0.994 & 0.985 & 1.000 & 0.000 & 0.000 & 0.000 & 0.978 & 0.000 & 0.961 & 0.994 & 0.957 & 1.000 & 7.870 & 5 \\
\hline$A_{2}$ & 0.000 & 1.000 & 0.743 & 0.951 & 1.000 & 1.000 & 0.904 & 0.981 & 0.923 & 0.983 & 0.997 & 1.000 & 10.482 & 1 \\
\hline$A_{3}$ & 1.000 & 0.000 & 0.956 & 0.920 & 0.955 & 0.975 & 0.978 & 0.809 & 1.000 & 0.000 & 0.992 & 0.000 & 8.585 & 4 \\
\hline$A_{4}$ & 0.993 & 0.990 & 0.000 & 1.000 & 0.976 & 1.000 & 1.000 & 1.000 & 0.000 & 1.000 & 0.000 & 0.917 & 8.877 & 3 \\
\hline$A_{5}$ & 0.959 & 0.702 & 0.740 & 0.740 & 1.000 & 0.992 & 0.000 & 0.996 & 1.000 & 0.983 & 1.000 & 0.992 & 10.104 & 2 \\
\hline
\end{tabular}

Table 9. Final ranking results of the suppliers

\begin{tabular}{|c|c|c|c|c|c|}
\hline Supplier & $Z_{i a}$ & $Z_{i b}$ & $Z_{i c}$ & $Z_{i}$ & Final ranking \\
\hline$A_{1}$ & 0.173 & 2.127 & 0.756 & 1.671 & 5 \\
\hline$A_{2}$ & 0.228 & 2.632 & 0.999 & 2.129 & 1 \\
\hline$A_{3}$ & 0.186 & 2.091 & 0.815 & 1.713 & 4 \\
\hline$A_{4}$ & 0.195 & 2.460 & 0.856 & 1.914 & 3 \\
\hline$A_{5}$ & 0.218 & 2.358 & 0.955 & 1.966 & 2 \\
\hline
\end{tabular}


Table 10. Comparative analysis with the PL-VIKOR method

\begin{tabular}{|c|c|c|c|c|c|c|c|c|}
\hline \multirow{2}{*}{ Supplier } & \multicolumn{2}{|c|}{$\begin{array}{c}\text { CoCoSo (New probability } \\
\text { aggregation method) }\end{array}$} & \multicolumn{2}{|c|}{$\begin{array}{c}\text { CoCoSo (Ref. probability } \\
\text { aggregation method) }\end{array}$} & \multicolumn{2}{|c|}{$\begin{array}{c}\text { VIKOR (New probability } \\
\text { aggregation method) }\end{array}$} & \multicolumn{2}{|c|}{$\begin{array}{c}\text { VIKOR (Ref. probability } \\
\text { aggregation method) }\end{array}$} \\
\cline { 2 - 9 } & $Z_{i}$ & Final ranking & $Z_{i}$ & Final ranking & $R_{i}$ & Final ranking & $R_{i}$ & Final ranking \\
\hline$A_{1}$ & 1.671 & 5 & 1.679 & 5 & 0.446 & 2 & 0.384 & 3 \\
\hline$A_{2}$ & 2.129 & 1 & 2.139 & 1 & 0.314 & 1 & 0.280 & 1 \\
\hline$A_{3}$ & 1.713 & 4 & 1.763 & 4 & 0.500 & 3 & 0.369 & 2 \\
\hline$A_{4}$ & 1.914 & 3 & 1.902 & 3 & 0.500 & 3 & 0.505 & 4 \\
\hline$A_{5}$ & 1.966 & 2 & 1.925 & 2 & 0.658 & 5 & 0.780 & 5 \\
\hline
\end{tabular}

\subsection{Results and discussions}

From Tables 7 and 8, we can find that if the poor performances of a component supplier under some criteria can be completely compensated by the good performances of the supplier under other criteria, the weak ranking of the suppliers is $A_{4}>A_{2}>A_{1}>A_{5}>A_{3}$; while if the good performances of an supplier under some criteria cannot fully compensate for the poor performances under other criteria, we get another weak ranking of the suppliers as $A_{2}>A_{5}>A_{4}>A_{3}>A_{1}$. When the compensation among the criteria is considered neutral, according to the aggregation strategies of the CoCoSo method, we obtain the strong ranking of the component suppliers as $A_{2}>A_{5}>A_{4}>A_{3}>A_{1}$. Thus, we recommend supplier $A_{2}$ as the optimum candidate.

To verify the effectiveness and robustness of the proposed hybrid multi-expert MCDM model, a comparative analysis is conducted. Since we have already analyzed the advantages of our new probability aggregation approach compared with the probability aggregation method proposed by Wu and Liao (2018) in Section 2.2, we will not repeat here but directly conduct a comparative analysis by applying another classical utility value-based ranking method, PL-VIKOR, in this part. The results are listed in Table 10. From the yielded results, we can see that, although the comprehensive scores of two probability aggregation methods are not the same, the final ranking results of the suppliers are the same. However, there are relatively large fluctuations for the raking results of the VIKOR-based model, which can show the robustness of our proposed hybrid model.

\section{Conclusions}

The whole-decoration residential products success of property developers depends on the reliability of a supply network and trustable suppliers. A suitable supplier choosing not only can guarantee the quality of a residential product, but also can reduce its developmental cost and decrease the housing price accordingly. It is beneficial to both property developers and buyers. This paper studied a new multi-expert MCDM method for property developers to select the most suitable construction component supplier in the process of promoting their residential whole- decoration strategy. Considering experts are not always knowledgeable enough to present information about the criteria in terms of precise values in a qualitative evaluation process, the HFLTS was taken to express the preferences of experts since it is closer to human cognition and perceptions. In addition, to enable a realistic presentation of the collective evaluations of a group, on the basis of interval rough boundaries derived by the rough set theory, we introduced a novel probabilistic aggregation approach. Then, the proposed novel probabilistic aggregation approach was applied to the MCDM problem for property developers to construct a hybrid MCDM model. The novel probabilistic aggregation-based BWM was used to derive the weights of criteria while the novel probabilistic aggregation-based CoCoSo method was developed to find the optimal supplier. The specific operation steps of the multi-expert MCDM model were given.

Considering the effectiveness and practicability of the proposed hybrid MCDM model, our model can also be applied to other group decision-making areas to deal with the uncertainty and vagueness in the decision-making process. In the proposed new probabilistic aggregation approach, we used the geometric average operator to integrate the defined accuracy degree to the original aggregated probability. Although the diversity of experts' perceptions were presented, the small probabilities of the PLTS in the aggregated judgment was increased, which seems with some defects. In the future, we shall research a more suitable operator for integration.

\section{Funding}

The work was supported by the National Natural Science Foundation of China under Grant 71771156 and Grant 71971145 .

\section{Author contributions}

Zhiying ZHANG and Huchang LIAO proposed the original idea and conceived the study. Zhiying Zhang and Huchang LIAO were responsible for developing the method, collecting and analyzing the data. Abdullah ALBARAKATI, Edmundas Kazimieras ZAVADSKAS and Jurgita ANTUCHEVIČIENE were responsible for data 
interpretation. Zhiying Zhang and Huchang LIAO wrote the first draft of the article. Abdullah AL-BARAKATI, Edmundas Kazimieras ZAVADSKAS and Jurgita ANTUCHEVIČIENE revised the paper.

\section{Disclosure statement}

The authors have no competing financial, professional, or personal interests from other parties that are related to this paper.

\section{References}

Corrente, S., Greco, S., \& Słowiński, R. (2013). Multiple criteria hierarchy process with ELECTRE and PROMETHEE. Omega, 41(5), 820-846. https://doi.org/10.1016/j.omega.2012.10.009

Eshtehardian, E., Ghodousi, P., \& Bejanpour, A. (2013). Using ANP and AHP for the supplier selection in the construction and civil engineering companies: case study of Iranian company. KSCE Journal of Civil Engineering, 17(2), 262-270. https://doi.org/10.1007/s12205-013-1141-Z

Gou, X. J., Liao, H. C., Xu, Z. S., \& Herrera, F. (2017). Double hierarchy hesitant fuzzy linguistic term set and MULTIMOORA method: a case of study to evaluate the implementation status of haze controlling measures. Information Fusion, 38, 22-34. https://doi.org/10.1016/j.inffus.2017.02.008

Greco, S., Matarazzo, B., \& Slowinski, R. (2001). Rough sets theory for multicriteria decision analysis. European Journal of Operational Research, 129(1), 1-47. https://doi.org/10.1016/S0377-2217(00)00167-3

Herrera, F., Herrera-Viedma, E., \& Verdegay, J. L. (1995). A sequential selection process in group decision making with a linguistic assessment approach. Information Sciences, 85(4), 223-239. https://doi.org/10.1016/0020-0255(95)00025-K

Lam, K. C., Tao, R., \& Lam, M. C. K. (2010). A material supplier selection model for property developers using fuzzy principal component analysis. Automation in Construction, 19(5), 608-618. https://doi.org/10.1016/j.autcon.2010.02.007

Li, H., Li, D., Zhai, Y., Wang, S., \& Zhang, J. (2016). A novel attribute reduction approach for multi-label data based on rough set theory. Information Sciences, 367, 827-847. https://doi.org/10.1016/j.ins.2016.07.008

Liao, H. C., \& Wu, X. L. (2020). DNMA: a double normalizationbased multiple aggregation method for multi-expert multicriteria decision making. Omega, 94, 102058. https://doi.org/10.1016/j.omega.2019.04.001

Liao, H. C., Jiang, L. S., Lev, B., \& Fujita, H. (2019a). Novel operations of PLTSs based on the disparity degrees of linguistic terms and their use in designing the probabilistic linguistic ELECTRE III method. Applied Soft Computing, 80, 450-464. https://doi.org/10.1016/j.asoc.2019.04.018

Liao, H. C., Mi, X. M., \& Xu, Z. S. (2020). A survey of decisionmaking methods with probabilistic linguistic information: bibliometrics, preliminaries, methodologies, applications and future directions. Fuzzy Optimization and Decision Making, 19(1), 81-134. https://doi.org/10.1007/s10700-019-09309-5

Liao, H. C., Mi, X. M., Yu, Q., \& Luo, L. (2019b). Hospital performance evaluation by a hesitant fuzzy linguistic best worst method with inconsistency repairing. Journal of Cleaner Production, 232, 657-671. https://doi.org/10.1016/j.jclepro.2019.05.308

Liao, H. C., Wen, Z., \& Liu, L. L. (2019c). Integrating BWM and ARAS under hesitant linguistic environment for digital sup- ply chain finance supplier selection. Technological and Economic Development of Economy, 25(6), 1188-1212. https://doi.org/10.3846/tede.2019.10716

Liao, H. C., Xu, Z. S., \& Zeng, X. J. (2014). Hesitant fuzzy linguistic VIKOR method and its application in qualitative multiple criteria decision making. IEEE Transactions on Fuzzy Systems, 23(5), 1343-1355.

https://doi.org/10.1109/TFUZZ.2014.2360556

Liao, H. C., Xu, Z. S., Herrera-Viedma, E., \& Herrera, F. (2018). Hesitant fuzzy linguistic term set and its application in decision making: a state-of-the art survey. International Journal of Fuzzy Systems, 20(7), 2084-2110. https://doi.org/10.1007/s40815-017-0432-9

Liao, H. C., Xu, Z. S., Zeng, X. J., \& Merigó, J. M. (2015). Qualitative decision making with correlation coefficients of hesitant fuzzy linguistic term sets. Knowledge-Based Systems, 76, 127-138. https://doi.org/10.1016/j.knosys.2014.12.009

Luo, Z., He, J., Pan, H., \& Yang, Y. (2016). Research on the selection strategy of green building parts supplier based on the catastrophe theory and Kent index method. Advances in Materials Science and Engineering, 2016, 1-12. https://doi.org/10.1155/2016/4673526

Matić, B., Jovanović, S., Das, D. K., Zavadskas, E. K., Stević, Ž., Sremac, S., \& Marinković, M. (2019). A new hybrid MCDM model: Sustainable supplier selection in a construction company. Symmetry, 11(3), 353.

https://doi.org/10.3390/sym11030353

Mi, X. M., Liao, H. C., Wu, X. L., \& Xu, Z. S. (2020). Probabilistic linguistic information fusion: a survey on aggregation operators in terms of principles, definitions, classifications, applications and challenges. International Journal of Intelligent Systems, 35(3), 529-556. https://doi.org/10.1002/int.22216

Mi, X. M., Tang, M., Liao, H. C., Shen, W. J., \& Lev, B. (2019). The state-of-the-art survey on integrations and applications of the best worst method in decision making: why, what, what for and what's next? Omega, 87, 205-225. https://doi.org/10.1016/j.omega.2019.01.009

Ministry of Housing and Urban-Rural Development of the People's Republic of China. (1999). Several opinions on promoting the modernization of housing industry and improving the quality of housing. http://www.mohurd.gov.cn/wjfb/200611/ t20061101_155382.html

Ministry of Housing and Urban-Rural Development of the People's Republic of China. (2008). Notice on further strengthening the management of residential fit-out and decoration. Ministry of Housing and Urban-Rural Development of the People's Republic of China. http://www.gov.cn/zwgk/200808/01/content_1061518.htm

Ministry of Housing and Urban-Rural Development of the People's Republic of China. (2013). Green building action plan. http://www.gov.cn/zwgk/2013-01/06/content_2305793.htm

Onar, S. Ç., Büyüközkan, G., Öztayşi, B., \& Kahraman, C. (2016). A new hesitant fuzzy QFD approach: an application to computer workstation selection. Applied Soft Computing, 46, 1-16. https://doi.org/10.1016/j.asoc.2016.04.023

Pamučar, D., Mihajlović, M., Obradović, R., \& Atanasković, P. (2017). Novel approach to group multi-criteria decision making based on interval rough numbers: hybrid DEMATELANP-MAIRCA model. Expert Systems with Applications, 88, 58-80. https://doi.org/10.1016/j.eswa.2017.06.037

Pamučar, D., Petrović, I., \& Ćirović, G. (2018). Modification of the Best-Worst and MABAC methods: a novel approach based on interval-valued fuzzy-rough numbers. Expert Systems with Applications, 91, 89-106. https://doi.org/10.1016/j.eswa.2017.08.042 
Pang, Q., Wang, H., \& Xu, Z. (2016). Probabilistic linguistic term sets in multi-attribute group decision making. Information Sciences, 369, 128-143.

https://doi.org/10.1016/j.ins.2016.06.021

Rezaei, J. (2015). Best-worst multi-criteria decision-making method. Omega, 53, 49-57. https://doi.org/10.1016/j.omega.2014.11.009

Rezaei, J. (2016). Best-worst multi-criteria decision-making method: some properties and a linear model. Omega, 64, 126-130. https://doi.org/10.1016/j.omega.2015.12.001

Rodriguez, R. M., Martinez, L., \& Herrera, F. (2011). Hesitant fuzzy linguistic term sets for decision making. IEEE Transactions on Fuzzy Systems, 20(1), 109-119. https://doi.org/10.1109/TFUZZ.2011.2170076

Safa, M., Shahi, A., Haas, C. T., \& Hipel, K. W. (2014). Supplier selection process in an integrated construction materials management model. Automation in Construction, 48, 64-73. https://doi.org/10.1016/j.autcon.2014.08.008

Seth, D., Nemani, V. K., Pokharel, S., \& Al Sayed, A. Y. (2018). Impact of competitive conditions on supplier evaluation: a construction supply chain case study. Production Planning \& Control, 29(3), 217-235. https://doi.org/10.1080/09537287.2017.1407971

Shi, Q., Zuo, J., \& Zillante, G. (2012). Exploring the management of sustainable construction at the programme level: a Chinese case study. Construction Management and Economics, 30(6), 425-440. https://doi.org/10.1080/01446193.2012.683200

Song, W. Y., Ming, X. G., \& Wu, Z. Y. (2013). An integrated rough number-based approach to design concept evaluation under subjective environments. Journal of Engineering Design, 24(5), 320-341. https://doi.org/10.1080/09544828.2012.732994

Stević, Ž., Pamučar, D., Vasiljević, M., Stojić, G., \& Korica, S. (2017). Novel integrated multi-criteria model for supplier selection: case study construction company. Symmetry, 9(11), 279. https://doi.org/10.3390/sym9110279

Torra, V. (1996). Negation functions based semantics for ordered linguistic labels. International Journal of Intelligent Systems, 11(11), 975-988. https://doi.org/10.1002/(SICI)1098111X(199611)11:11<975::AID-INT5>3.0.CO;2-W

Wang, T. K., Zhang, Q., Chong, H. Y., \& Wang, X. (2017). Integrated supplier selection framework in a resilient construction supply chain: an approach via analytic hierarchy process (AHP) and grey relational analysis (GRA). Sustainability, 9(2), 289. https://doi.org/10.3390/su9020289

Wen, Z., Liao, H. C., Zavadskas, E. K., \& Al-BaIrakati A. (2019). Selection third-party logistics service providers in supply chain finance by a hesitant fuzzy linguistic combined compromise solution method. Economic Research-Ekonomska
Istrazivanja, 32(1), 4033-4058. https://doi.org/10.1080/1331 677X.2019.1678502

Wu, X. L., \& Liao, H. C. (2018). An approach to quality function deployment based on probabilistic linguistic term sets and ORESTE method for multi-expert multi-criteria decision making. Information Fusion, 43, 13-26.

https://doi.org/10.1016/j.inffus.2017.11.008

Wu, X. L., \& Liao, H. C. (2019). A consensus-based probabilistic linguistic gained and lost dominance score method. European Journal of Operational Research, 272(3), 1017-1027. https://doi.org/10.1016/j.ejor.2018.07.044

$\mathrm{Xu}, \mathrm{Z}$. S. (2005). Deviation measures of linguistic preference relations in group decision making. Omega, 33(3), 249-254. https://doi.org/10.1016/j.omega.2004.04.008

Yazdani, M., Wen, Z., Liao, H. C., Banaitis, A., \& Turskis, Z. (2019a). A grey combined compromise solution (CoCoSo-G) method for supplier selection in construction management. Journal of Civil Engineering and Management, 25(8), 858-874. https://doi.org/10.3846/jcem.2019.11309

Yazdani, M., Zarate, P., Zavadskas, E. K., \& Turskis, Z. (2019b). A combined compromise solution (CoCoSo) method for multi-criteria decision-making problems. Management Decision, 57(9), 2501-2519. https://doi.org/10.1108/MD-05-2017-0458

Yin, S., Li, B. Z., Dong, H. M., \& Xing, Z. Y. (2017). A new dynamic multicriteria decision-making approach for green supplier selection in construction projects under time sequence. Mathematical Problems in Engineering, 2017, 1-13. https://doi.org/10.1155/2017/7954784

Zadeh, L. A. (1975). The concept of a linguistic variable and its application to approximate reasoning-I. Information Sciences, 8(3), 199-249. https://doi.org/10.1016/0020-0255(75)90036-5

Zhai, L. Y., Khoo, L. P., \& Zhong, Z. W. (2008). A rough set enhanced fuzzy approach to quality function deployment. The International Journal of Advanced Manufacturing Technology, 37(5-6), 613-624. https://doi.org/10.1007/s00170-007-0989-9

Zhang, X., Shen, L., \& Wu, Y. (2011). Green strategy for gaining competitive advantage in housing development: a China study. Journal of Cleaner Production, 19(2-3), 157-167. https://doi.org/10.1016/j.jclepro.2010.08.005

Zhang, Y. X., Xu, Z. S., \& Liao, H. C. (2017). A consensus process for group decision making with probabilistic linguistic preference relations. Information Sciences, 414, 260-275. https://doi.org/10.1016/j.ins.2017.06.006

Zhu, G. N., Hu, J., Qi, J., Gu, C. C., \& Peng, Y. H. (2015). An integrated AHP and VIKOR for design concept evaluation based on rough number. Advanced Engineering Informatics, 29(3), 408-418. https://doi.org/10.1016/j.aei.2015.01.010 